\title{
Why preen others? Predictors of allopreening in parrots and corvids and comparisons to grooming in great apes
}

\section{Short running title: Allopreening in parrots and corvids}

Alejandra Morales Picard ${ }^{1,2}$, Roger Mundry ${ }^{3,4}$, Alice M. Auersperg ${ }^{3}$, Emily R. Boeving ${ }^{5}$, Palmyre H. Boucherie ${ }^{6,7}$, Thomas Bugnyar ${ }^{8}$, Valérie Dufour ${ }^{9}$, Nathan J. Emery ${ }^{10}$, Ira G. Federspiel $^{8,11}$, Gyula K. Gajdon ${ }^{3}$, Jean-Pascal Guéry ${ }^{12}$, Matjaž Hegedič ${ }^{8}$, Lisa Horn ${ }^{8}$, Eithne Kavanagh $^{1}$, Megan L. Lambert ${ }^{1,3}$, Jorg J. M. Massen ${ }^{8,13}$, Michelle A. Rodrigues ${ }^{14}$, Martina Schiest $1^{15}$, Raoul Schwing ${ }^{3}$, Birgit Szabo ${ }^{8,16}$, Alex H. Taylor ${ }^{15}$, Jayden O. van Horik ${ }^{17}$, Auguste M. P. von Bayern ${ }^{18}$, Amanda Seed ${ }^{19}$, Katie E. Slocombe ${ }^{1}$

${ }^{1}$ Department of Psychology, University of York, UK

${ }^{2}$ Montgomery College, Rockville, Maryland, USA

${ }^{3}$ Messerli Research Institute, University of Veterinary Medicine Vienna, Medical University Vienna, University of Vienna, Vienna, Austria.

${ }^{4}$ Platform Bioinformatics and Biostatistics, University of Veterinary Medicine Vienna, Austria.

${ }^{5}$ Department of Psychology, Florida International University, Miami, FL, USA

${ }^{6}$ Institut Pluridisciplinaire Hubert Curien, University of Strasbourg, 23 rue Becquerel 67087 Strasbourg, France

${ }^{7}$ Centre National de la Recherche Scientifique, UMR 7178, 67087 Strasbourg, France

${ }^{8}$ Department of Cognitive Biology, University of Vienna, Vienna, Austria

${ }^{9}$ UMR Physiologie de la Reproduction et des Comportements, INRA-CNRS-Université de Tours -IFCE, 37380 Nouzilly, France

${ }^{10}$ School of Biological \& Chemical Sciences, Queen Mary University of London, London, England

${ }^{11}$ University of Cambridge, UK

${ }^{12}$ Vallée des Singes Primate Park, Romagne, France

${ }^{13}$ Animal Ecology Group, Utrecht University, Utrecht, The Netherlands

${ }^{14}$ Beckman Institute for Advanced Science and Technology, University of Illinois, Urbana, USA

${ }^{15}$ School of Psychology, University of Auckland, Auckland, New Zealand

${ }^{16}$ Department of Biological Sciences, Macquarie University, Sydney, Australia

${ }^{17}$ Centre for Research in Animal Behaviour, Psychology, University of Exeter, UK

${ }^{18}$ Max-Planck-Institute for Ornithology, Seewiesen, Germany

${ }^{19}$ School of Psychology and Neuroscience, University of St Andrews, UK 


\section{Acknowledgements}

35 At Lincolnshire Wildlife Park we thank Steve Nichols and staff for their support. For the research conducted at La Foa, Province Sud, New Caledonia, we thank Province Sud for

37 granting us permission to work in New Caledonia and Dean M. and Boris C. for allowing us access to their properties for catching and releasing the crows. For the research conducted at the

39 Columbus Zoo we thank Audra Meinelt and the keeper staff. At North Carolina Zoo, we thank 40 Corinne Kendall, Richard Bergl, Jennifer Ireland, as well as keeper staff, Steve Ross, and The 41 Chimpanzee Species Survival Plan. For research conducted at Vallee des Singes Primate Park 42 and Leipzig zoo, we thank keeper staff, La Conservatoire pour la Protection des Primates, and 43 Matthew Henderson for help with data collection. At Edinburgh Zoo we thank Emma Wallace, 44 Stuart Watson and Ruth Sonnweber for data collection, the keepers of Budongo Trail and Royal 45 Zoological Society of Scotland for permission to collect data. At Loro Parque (Max-Planck46 Comparative Cognition Research Station, Animal Embassy), we cordially thank Wolfgang and 47 Christoph Kiessling and the Loro Parque Fundación for their support of our research, as well as 48 Dr. Anastasia Krasheninnikova for coordinating data collection, and Nina Buffenoir, Claudia 49 Zeiträg, and other lab members for data collection. At University of Vienna, we thank the staff 50 and students at Haidlhof Research Station. We are grateful to Stuart Watson for statistical 51 advice. Megan L. Lambert was funded by an Overseas Research Scholarship from the University 52 of York. Alex H. Taylor and Martina Schiestl's research was supported by a Royal Society of 53 New Zealand Rutherford Discovery Fellowship. Nathan Emery was supported by a Royal 54 Society University Research Fellowship, as well as the University of Cambridge and Queen 55 Mary University of London. None of the authors have any conflicting interests to report. 


\section{Abstract}

Allogrooming in primates serves not only a hygienic function, but also plays a crucial role

59 in maintaining strong affiliative bonds between group members, which in turn, underpin the emergence of cooperative behavior. In contrast, although allopreening occurs in many avian

61 species, we know little about its social functions. Our study addresses this issue by investigating

62 allopreening in a broad comparative data set including six corvid and nine parrot species. We

63 assessed whether rates of allopreening initiations, proportion of time spent allopreening, and the

64 number of grooming partners in captive group-housed birds were comparable to patterns observed

65 in captive chimpanzees and bonobos. While parrots and corvids were found to have similar rates

66 of social grooming to bonobos and chimpanzees, $P$ an species dedicated significantly more time to

67 social grooming. Animals in larger groups had more grooming partners, but when controlling for

68 the number of potential partners, birds tended to have fewer grooming interaction partners than

69 Pan species. We then investigated whether allopreening in parrots and corvids was predicted by

70 behavioral markers of affiliative social bonds (close physical proximity, active feeding, and low

71 levels of agonistic behavior). Results revealed that providing allopreening to a partner was

72 significantly predicted by often being in close proximity, but not engagement in active feeding or

73 agonistic behavior. We examined the region allopreened in a subset of species and found that

74 preening a partner's head was predicted by both close physical proximity and active feeding, while

75 body allopreening was only predicted by close physical proximity. Head preening may confer

76 more hygienic benefits to recipients, and thus may be more selectively provided to valued partners.

77 Results support the hypothesis that allopreening in corvids and parrots helps maintain social bonds

78 with an individual's most important social partners, showing some similarities to allogrooming in

79 primates. 
80 Keywords: parrots, corvids, primates, allopreening, allogrooming, social bonds, affiliative

81 relationships

\section{Introduction} forms of affiliative behavior (Dunbar, 1991; Emery et al., 2007; Fraser \& Bugnyar 2010; Carter \& Leffer, 2015; Kenny et al., 2017; Kutsukake \& Clutton-Brock, 2006; Watts, 2000; Zabel et al.,

87 1992). Investigations looking into the adaptive value of social grooming (known as allogrooming in mammals and allopreening in birds) have identified two main categories of potential functions.

89 One category consists of hygienic benefits (e.g., maintaining good skin/fur/feather condition through the removal of ectoparasites, dirt, or debris; Akinyi et al., 2013; Brooke, 1985; Clayton et.

91 al., 2010; Mooring, 1995), while the other identifies social functions (e.g., facilitating the 92 formation and maintenance of partnerships; di Bitetti, 1997; Gill, 2012; Henazi \& Barrett, 1999;

93 Kenny et al., 2017; Kutsukake \& Clutton-Brock, 2006). Note that these benefits are not necessarily 94 mutually exclusive. Evidence supporting the social function hypothesis has come from a range of species (e.g., vampire bats, Desmodus rotundus, Carter \& Leffer, 2015; herb-field mice, Apodemus microps, Stopka \& Graciasová, 2001; meerkats, Suricata suricatta, Kutsukake \& Clutton-Brock, 2006; cows, Bos Taurus, Val-Laillet et al., 2009), with primate research producing some of the most compelling evidence.

The body of research on primate allogrooming is extensive and suggests that social grooming likely confers several evolutionary advantages for animals living in socially complex environments. Although grooming confers an important hygienic benefit to recipients through the removal of parasites, the time primates dedicate to grooming is better explained by group size than 
103 body size, suggesting grooming plays a social function in addition to a hygienic function (Dunbar, 104 1991). In primates, like in various other species, individuals do not groom others at random, but 105 are instead selective with whom they provide this service to; individuals are more likely to groom 106 kin, reproductive partners, and dominant individuals (di Bitetti, 1997; Call et al., 1996; Franz, 107 1999; Gill, 2012; Gilby \& Wrangham, 2008; Ju \& Lee, 2016; Koyama et al., 2012; Kutsukake \& 108 Clutton-Brock, 2006; Massen et al. 2012; O'Brien, 1993; Schino, 2001; Silk et al., 2006; Seyfarth, 109 1977). Allogrooming is also associated with alliance formation and the maintenance of cooperative 110 alliances (Berghänel et al. 2011; di Bitetti, 1997; Seyfarth \& Cheney, 1984; Watts, 2000). Primate 111 studies also indicate that the fostering of reciprocity may be one of the key advantages derived 112 from grooming partners (e.g., exchanging grooming for access to food or assistance during 113 agonistic encounters with others; Barrett et al.,1999; De Waal, 1997; Schino, 2006; Ventura et al., 114 2006). Furthermore, there is evidence that allogrooming reduces individual stress and group 115 tension (e.g., reduction of heart rate, cortisol concentrations, and de-escalating aggressive 116 interactions; Aureli et al., 1999; Feh \& de Mazières, 1993; Schino et al., 1988; Wittig et al., 2008; 117 Young et al., 2014). among some avian groups, such as Psittaciformes, it has not been found among most birds (Kenny 120 et al., 2017) and has not attracted the same research effort to understand its function as 121 allogrooming has in mammals such as primates. The absence of allopreening in large numbers of 122 avian species indicates that, unlike autopreening (self-preening), it is not vital to the maintenance 123 of good feather condition, which is necessary for flight. Instead, explanations for the occurrence 124 of this behavior appear to be found in the social organization of avian species. Previous research, 125 for instance, has indicated that allopreening is most likely to occur among birds that live in 
126 colonies, family groups, or that maintain stable partnerships (Brooke, 1985; Clayton \& Emery, 127 2007; Gill, 2012; Kenny et al., 2017; Lewis et al., 2007; Seibert, 2006). The fact that allopreening 128 is most commonly found among birds that live in close physical proximity with conspecifics is 129 consistent with the hygienic function of allopreening, as preening partners would help control 130 ectoparasitic infestation among group members. This is supported by the fact that ectoparasitic 131 infestation rates have been found to be higher in gregarious bird species (Boyd, 1951; Poulin,1991; 132 Rifkin et al., 2012), and among those species, non-paired birds have been found to have higher 133 infestation rates than paired birds that regularly allopreen (e.g., Macaroni Penguins, Eudyptes 134 chrysolophus, Brooke, 1985). Ectoparasitic infestation rates are also generally higher in the head 135 and neck regions, as these areas cannot be autopreened (Boyd, 1951; Cox, 2012). While these 136 findings indicate that allopreening may play a significant role in helping some avian species 137 maintain good physical condition, there is also evidence it is not the sole function of allopreening. As is the case with primates, there is reason to believe that allopreening may have initially evolved to serve hygienic functions but became adapted to serve social functions as well. Evidence 140 supporting this assertion comes from Kenny et al.'s (2017) large-scale comparative study 141 (including 503 species from 116 avian families), which revealed that allopreening most commonly 142 occurs among species in which cooperative bi-parental care is necessary for offspring survival. 143 Their analyses also showed that pair bond stability was predicted by whether allopreening between 144 partners was known to occur in a species; species that allopreened showed significantly lower 145 divorce rates between breeding seasons (e.g., species belonging to Procellariiforme and 146 Psittaciforme orders). The findings from Kenny et al's (2017) study, which also included 147 phylogenetic analyses, suggest that allopreening developed as a facilitator of bond strength for 148 species whose reproductive strategies require individuals to form stable and cooperative 
149 partnerships to successfully rear offspring. Previous research focusing on intra-species variation 150 in pair bond relationship quality also provides support for this conclusion. Gill (2012), for instance, 151 found that divorce rates were higher for wren (Cantorchilus leucotis) pairs that were not observed 152 allopreening as compared to those that frequently and consistently preened each other. Similarly, 153 Spoon et al. (2006; 2007) found that allopreening behavior predicted pair bond stability. 154 Furthermore, they found that relationship quality (which included allopreening measures) was 155 predictive of egg production and offspring survival rate, with successful pairs showing more 156 effective coordination of bi-parental care.

Allopreening occurs predominately among mated pairs (though not exclusively, e.g. Miyazawa et al. in this issue) and appears to play a substantial role in some species' courtship 159 behavior (Clayton et al., 2010; Erickson, 1973; Forsman \& Wight, 1979; Kushlan, 2011). Studies 160 also indicate that allopreening assists in re-establishing familiarity after periods of separation 161 (Black, 1996; Erickson, 1973; Kushlan, 2011). Although allopreening appears to be most common 162 between reproductive partners, allopreening between same-sex pairs is also documented in various 163 species (e.g., zebra finches, Taeniopygia guttata, Tomaszycki \& Zatirka, 2014; budgerigars, 164 Melopsittacus undulates, Abbassi \& Burley, 2012; large billed crows, C. macrorhynchos, 165 Miyazawa et al. this issue; ravens, Corvus corax, Fraser \& Bugnyar 2010; rooks, Corvus 166 frugilegus, Boucherie et al., 2016, Emery et al., 2007). Studies also found evidence of preference 167 of siblings over non-siblings for preening partners in juvenile birds (Fraser \& Bugnyar, 2010; 168 Garnetzke-Stollmann \& Franck, 1991; Ju \& Lee, 2016). Furthermore, research on avian species 169 that demonstrate dominance hierarchies in their social organization indicate that in some species 170 dominant individuals are more likely to be the recipients of preening from subordinate group 171 members (e.g., green woodhoopoe, Phoeniculus purpureus, Radford \& Du Plessis, 2006). 
172 Research on a colonial species (common guillemots, Uria aalge) also provides evidence that

173 allopreening serves as a mechanism for the reduction of aggression; between pairs breeding in

174 close physical proximity, agonistic rates were negatively correlated with allopreening and breeding

175 success (Lewis et al., 2007). Allopreening has also been found to be predictive of agonistic support.

176 In a study of captive group-housed ravens, Fraser and Bugnyar (2012) found that individuals were

177 more likely to provide aid to group members they received preening from, even after controlling

178 for "symmetry-based reciprocity" (including kin, same sex, same rank).

Previous studies on avian allopreening have provided us with pockets of insight into this seemingly complex behavior. Although preliminary research suggests that allopreening plays an equally important role in meeting challenges of social life in some avian species as allogrooming

182 does in primates, the extent to which that is true is not yet fully known. One reason why this is the 183 case is that investigations which directly compare birds to primates on social grooming measures 184 are lacking. The vast phylogenetic separation between these taxa and the absence of social 185 grooming in the majority of bird species suggests that social grooming represents an example of 186 convergence. Evidence of cognitive complexity in parrots (birds belonging to the Psittaciforme 187 order) and corvids (birds belonging to the Corvidae family, commonly referred to as the crow 188 family), which in some cases appears to be comparable to great ape intelligence (Emery \& Clayton, 189 2004; Güntürkün \& Bugnyar, 2016; Lambert et al., 2018), also indicates that bird and primate taxa 190 have experienced convergence in cognitive processes (Emery et al., 2007).

Parrots and corvids serve as ideal subjects for investigating the quality and functions of 192 allopreening. This behavior occurs in a variety of parrot and corvid species and appears to be 193 particularly widespread among parrots (Kennedy et al., 2017; Seibert, 2006). A common 194 characteristic of these avian taxa, which they share with many primates, is the presence of stable 
195 196

197

198

199

200

201

202

203

204

205

206

207

208

209

210

211

212

213

214

215

216

217

social bonds, often lasting several years (Clayton \& Emery, 2007; Seibert, 2006; Spoon, 2006).

These bonds are maintained throughout and across breeding seasons; in various parrot species, for instance, pair bonds may remain stable for more than a decade (Forshaw, 2006; Seibert, 2006). Evidence of complexity is also found in these partnerships. Research on ravens, for example, has shown that relationship quality is comprised of the same three components that make up many primate relationships: value (based on allopreening, proximity, agonistic support), compatibility (based on aggression, counter-intervention, tolerance to approaches), and security (based on variation in response to approach over time) (Fraser \& Bugnyar, 2010; Fraser et al., 2008). Another important characteristic of parrots and corvids is that they produce altricial young, which have long developmental periods and require substantial care from parents or reproductive helpers (such as in cooperative breeders; e.g. Horned and New Caledonian Parakeet (Eunymphicus cornutus, Cyanoramphus saisseti), Theuerkauf et al., 2009; Florida scrub-jay (Aphelocoma coerulescens), Clayton \& Emery, 2007). The stability of partnerships, and the effectiveness with which partners coordinate the care they provide to offspring, therefore have substantial fitness implications. This is supported by Spoon et al.'s (2006; 2007) research demonstrating an association between behavioral coordination and reproductive success in cockatiels. Effective parrot/corvid partners not only cooperate in the direct care of young (e.g., providing nourishment to chicks), but also in the protection of resources (e.g., nest sites; Renton, 2004) and in managing conflicts with conspecifics (Braun \& Bugnyar, 2012; Emery et al., 2007, Fraser \& Bugnyar, 2010b).

We argue that comparative examinations of social grooming quality in primates and birds, and its potential associations to social factors, provide a valuable opportunity for deepening our understanding of conditions that supported the likely convergent evolution of social bonding behaviors. The present study therefore had two main aims: (i) to offer a preliminary comparison 
218 of the social preening behavior in parrots and corvids, and social grooming in chimpanzees and

219 bonobos, in terms of the time dedicated to social grooming and diversity of social grooming

220 partners and (ii) to investigate whether social preening is associated with other affiliative social

221 behaviors and therefore serves as a reliable marker of bond strength in parrots and corvids, as has

222 previously been found in primates. Although a broad range of avian and primate species would be

223 ideal for such comparisons, the logistical challenges involved in obtaining directly comparable

224 measures from a wide variety of species, meant, in line with previous comparisons of cognition

225 (e.g., Emery \& Clayton, 2004), we had to focus our efforts on parrot and corvid species for birds

226 and chimpanzees and bonobos for primates. Using a large data set, representing nine parrot and

227 six corvid species, we assess the rate of grooming initiations, the proportion of time spent socially

228 grooming, and the diversity of grooming partners, in these captive birds and, additionally, in

229 captive groups of the two Pan species (bonobos and chimpanzees). It would be ideal to look at

230 wild rather than captive animals in these analyses, as the impact of captivity on the behaviors of

231 different species is unknown. However, as it is only possible to observe the social interactions of

232 most species of corvids and parrots in the wild at nest or roost sites, which is incomparable to the

233 full day follows that are possible for Pan species, our investigations necessarily had to focus on

234 captive populations.

235 In order to address our second aim, we investigated potential associations between

236 allopreening and three additional measures of relationship strength (proximity, active feeding, and

237 agonistic behavior). We focused on these measures/interactions because they serve as reliable

238 measures of relationship quality in a variety of species (Boucherie et al., 2016; Bräger et al., 1994;

239 Dunbar \& Shultz, 2010; Fraser \& Bugnyar, 2010; Gilby \& Wrangham, 2008; Spoon et al., 2006,

240 2007; Zabel et al., 1992). Maintenance of close physical proximity is widely used to measure 
241 relationship stability (Black, 2001; De Kort et al., 2006; Dunbar \& Shultz, 2010; Garroway \&

242 Broders, 2007; Gilby \& Wrangham, 2008; Emery et al., 2007; Massen et al. 2010; Möller et al.,

243 2001; Silk et al., 2006; Zabel et al., 1992). Among birds, active feeding may involve either

244 regurgitation into the mouth of a partner (known as allofeeding, Seibert, 2006) or transferring a

245 monopolizable food item to a partner's beak. This behavior commonly occurs between parents and

246 offspring, and between mates during egg incubation, but also occurs outside breeding contexts (De

247 Kort et al., 2006; Duque \& Stevens, 2016; Garnetzke-Stollmann, \& Franck, 1991; Pitter \&

248 Christiansen, 1997; Seibert, 2006; Smith, 1980; Spoon, 2006, von Bayern et al., 2007). Frequency

249 of agonistic interactions among social partners has been identified as indicative of bond strength

250 (Spoon, 2006). Rook pairs with high levels of affiliative behaviors have been found to show little

251 to no intrapair aggression (Emery et al., 2007), and Siberian jays (Perisoreus infaustus) were more

252 likely to direct aggression towards non-kin in a foraging context (Sklepkovych, 1997); time spent

253 in proximity, however, was not controlled for in these studies. Agonistic behavior has also been

254 used as a measure of behavioral compatibility, which has been found to be predictive of breeding

255 success (number of eggs laid and chicks reared to independence) and pair bond stability (extra-

256 pair copulation and divorce rates) in cockatiels (Spoon et al., 2006, 2007).

In our study, we also engaged in explorations of mutual allopreening (defined as two birds

258 simultaneously preening each other) and body region preened. While variation is found among

259 mammals in the occurrence of mutual allogrooming (e.g., it's highly common in Camargue horses,

260 Equus caballus, but appears to be rare (or absent) in Assamese macaques, Macaca assamensis,

261 Cooper \& Bernstein, 2000), it is unclear to what extent it serves as a meaningful indicator of

262 relationship quality. Studies on chimpanzee mutual allogrooming yielded mixed results in this

263 regard, with some research suggesting that it serves to strengthen bonds (Fedurek \& Dunbar, 
264 2009), while other findings indicate that it is used to prolong grooming bouts (Machanda et al.,

265 2014). By assessing mutual allopreening in birds we may gain some insight regarding its functions.

266 Similarly, little is currently known about the significance of variation in body region preened.

267 Although preening of the head and neck areas is relatively common among birds, there is inter-

268 species variation in how much individuals preen partners' bodies (Seibert, 2006). It is possible that

269 this variation may be explained by anatomical or social factors. For instance, species that possess

270 preen (uropygial) glands may be more likely to allopreen the body as the preen gland (dorsally

271 located at the tail base) secretes oil that must be spread throughout the body during preening. While

272 most species have preen glands (Elder, 1954), some birds maintain feathers through powder down,

273 which is secreted throughout the body. Thus, in those species, body preening may have less benefit.

274 However, inter-species (or intra-species) variation may be better explained by social factors such

275 as bond strength. For example, as head/neck preening cannot be achieved via autopreening, and

276 may be more valuable, so it may occur more frequently between dyads with strong bonds or

277 between kin.

We predicted that if social grooming has a social function in addition to a hygienic one in 279 parrots and corvids, they would show similar social grooming rates to Pan species. Based on 280 previous research suggesting that allopreening most commonly occurs between pair bond partners, 281 we expected that parrots and corvids would show less widely distributed allopreening, preening 282 fewer group members than bonobos and chimpanzees. If found, this might result in parrots and 283 corvids spending less time overall engaged in social grooming than Pan species. In terms of 284 addressing whether allopreening in corvids and parrots served as a marker of social bonds, we 285 hypothesized that allopreening would be positively predicted by physical proximity and active 286 feeding (i.e., individuals are more likely to preen partners they choose to maintain close physical 
287 contact to and/or actively feed). We also expected results to indicate that individuals are less likely

288 to direct aggression to group members they preened. Finally, for a subset of species for whom the

289 data were available, we also investigated inter-species variation in the occurrence of mutual

290 allopreening (defined as two birds simultaneously preening each other) and body region preened.

291 Species variation in percentage of allopreening that focused on the head versus the body was

292 assessed and compared to species' anatomical preening mechanisms (uropygial gland or powder

293 down) to determine whether they appeared to be associated. Potential associations between

294 location preened and social factors (proximity, active feeding, agonistic behavior) were also

295 investigated. These were explorative analyses, and as such, no specific predictions were made.

297 Methods

298 Study groups

299 The observational data we used for this study were obtained through a collaborative effort. Data 300 were collected at various sites on captive, group-housed $(3+$ individuals sharing a single species 301 enclosure) parrots (nine species, $N=99$ ), corvids ( 302 chimpanzees $(N=56)$. The majority of groups were mixed-age or consisted entirely of 303 adults/subadults. Four corvid groups were entirely composed of juvenile birds (one year or 304 younger at time of observation). Species, number of groups, group size, and group composition 305 (age and presence of breeding pairs; listed for descriptive purposes, not included in analyses) can 306 be seen in Table 1. For additional subject details and study site information see Table S1 in 307 supplementary material.

\section{Data collection}


310 Observational data on social behaviors were collected using individual focal sampling for three

311 out of nine Pan groups and 14 out of 23 groups of birds; group all-occurrence or scan sampling

312 was used for six Pan groups and nine bird groups (see Table 1). Proximity scan data were collected

313 using individual focal sampling for 10 bird groups; group focal sampling was used for 11 bird

314 groups; proximity data were not available for two species (black headed caiques, red shouldered

315 macaws; see Table 1). Length of observations varied among groups (2 min to $30 \mathrm{~min}$ ).

316

317 Measures

318 An overview of the measures used is given here, with more detailed information on definitions 319 and how measures were extracted across the different groups in the Supplementary methods. We 320 calculated three different measures of social grooming effort: (i) in two bird species and some Pan 321 groups instantaneous scan samples were recorded (see Table 1), enabling the proportion of scans 322 where an individual was engaged in social grooming to be calculated; (ii) for some groups, the 323 duration a focal individual spent engaging in social grooming was available, enabling the 324 calculation of proportion of time spent allogrooming; and (iii) some groups shared a similar 325 definition of allogrooming bout, so rate of allogrooming bouts could be calculated for these groups. 326 For more detailed analysis of allopreening behavior within some bird species, individual 327 allopreening behaviors were also coded. For individual behaviors, location being preened 328 (head/neck or body) and focal role (giver, recipient, or mutual) were identified; a change in body 329 region, focal role, or partner marked the end of one behavior and the start of another. Active 330 feeding (regurgitation into the mouth (allofeeding) or transfer of a monopolizable food item to the 331 mouth) and agonistic behavior were recorded for most bird groups using all occurrence sampling. 
332 Proximity data was collected using scan sampling for all bird groups and subjects' nearest

333 neighbors were identified during scans (see Table 1 for additional information on how nearest

334 neighbors were defined across our groups).

\section{Data Analysis}

337 We focused our statistical models on data obtained from animals that lived in mixed age or 338 adult/subadult groups where they had at least two potential grooming partners and more than 120 $339 \min (+/-5 \%)$ observation time. As data were not available for all groups for all measures and 340 variables we conducted analyses on subsets of available data. Thus, not all groups are included in 341 all analyses, and some analyses have larger sample sizes than others. To address our hypotheses, 342 we fitted a series of Generalized Linear Mixed Models (Baayen, 2008; GLMM). These differed in 343 the response variable investigated, the amount of available data, and, hence, also in sample sizes. 344 To keep type I error rate at the nominal level of 0.05 we included random slopes (Schielzeth \& 345 Forstmeier, 2009; Barr et al., 2013) for combinations of fixed and random effects as applicable. 346 Whenever a model comprised at least two key test predictors we conducted a full-null model 347 comparison. Such a full-null model comparison aims to avoid 'cryptic multiple testing' (which is 348 an issue whenever the number of predictors exceeds one) and reveals the overall significance 349 associated with the predictors being present in the full but not in the null model (Forstmeier \& 350 Schielzeth, 2011). Below we specify for each model which random slopes we included and which 351 predictors were dropped from the full model to obtain the null model. We are aware that for most 352 of the models it would be required to account for the phylogenetic relationships among the species. 353 However, we are not aware of well-established options allowing us to account for this within the 
354 framework of multilevel data (i.e., with repeated observations per species and individual and 355 multiple social groups per species). Hence, we used GLMMs instead.

357 Comparison of social grooming in birds and Pan species

358 Five GLMMs were conducted to compare different aspects of bird and Pan social grooming

359 (Models 1a-c; 2a-b). For these analyses we considered all grooming interactions the focal animal 360 was involved in, regardless of its role (recipient or provider). In order to assess whether taxon (bird 361 or Pan) could explain variation in the time dedicated to social grooming, we ran three separate 362 GLMMs on three different measures of grooming effort:

364 Proportion of time dedicated to social grooming in corvids, parrots and Pan species (Models 1a, $3651 b$ and $1 c)$

366 To estimate to what extent the proportion of time individuals spent allogrooming (Model 1a) was 367 influenced by taxon we fitted a GLMM with beta error distribution (Bolker, 2008) and logit link 368 function. Taxon was included as the key fixed effects predictor, but removed to obtain the null 369 model. To control for group size (number of potential grooming partners), group size was 370 included as an additional fixed effects covariate. As random intercept effects we included species 371 and group. The model was not overdispersed (dispersion parameter: 0.978) and collinearity was 372 not an issue (maximum Variance Inflation Factor, VIF: 1.043; see below). The sample for this 373 model consisted of a total of 125 proportions obtained from 14 groups in 11 species.

374 We fitted two further identical models with regard to the predictors but with slightly 375 varying response variables. In Model $1 \mathrm{~b}$ the response was the proportion of scans individuals 376 spent grooming. Neither collinearity (maximum VIF $=1.466$ ) nor overdispersion (dispersion 
377 parameter $=0.888)$ were an issue. However, the random effect of species comprised only four

378 levels making the assessment of its contribution unreliable. Hence, results for this model should

379 be treated cautiously. The sample for this model consisted of a total of 94 proportions, obtained

380 for 11 social groups in four species. In Model 1c the response was the rate of social grooming

381 initiations (number of social grooming bouts/observation time). Again, Model 1c did not present

382 an issue with collinearity (maximum VIF $=1.027$ ) and it also was not overdispersed (dispersion

383 parameter $=0.972$ ). The sample analyzed for this model comprised a total of 175 proportions,

384 obtained for 18 groups in 14 species. In Model $1 \mathrm{~b}$ we z-transformed group size to a mean of zero

385 and a standard deviation of one to ease model convergence.

Number of grooming interaction partners in corvids, parrots and Pan species (Models 2 a and 2b)

389 We tested whether taxon (bird or Pan) could explain variation in the diversity of grooming partners. As more partners are likely to be identified with increased observation time, we limited this analysis to the first 240 minutes (+/- 5\%) of observation for each animal. Thus, we only included individuals with at least one grooming event and 240 minutes of observation time in this analysis, resulting in $N=178$. To test whether the proportion of groupmates individuals 394 groomed with differed between Pan and birds we fitted a GLMM with binomial error structure and logit link function (McCullagh \& Nelder, 1989; Model 2a). The sole fixed effect (besides the 396 intercept) in this model was taxon with two levels (ape and bird). To avoid pseudo-replication, 397 we included random intercept effects for species and group ID into the model. The response in this model was the proportion of groupmates the individuals interacted with. Practically, we 399 modelled this by using a two-column matrix as the response which comprised the number of 
groupmates individuals groomed with and did not groom with as the response (Baayen, 2002).

401 To account for interaction propensities potentially varying among individuals we further

402 included a random effect of subject ID into this model. We dropped taxon from the full model to

403 obtain the null model. The model was not overdispersed (dispersion parameter $=0.778)$.

404

405

406

which the response was the total number of grooming interaction partners per individual and into

407 which we included group size as an additional fixed effect (Model 2b). This model was fitted

408 with a Poisson error structure. We removed the random effect of subject ID from this model, but

409 we included random slopes of the number of available interaction partners within group ID and

410 species into this model. Originally, we also included the parameters for the correlations between

411 random intercepts and slopes into this model, but, since these were both estimated to be

412 essentially 1 or -1 (being indicative of them being unidentifiable; Matuschek et al., 2017) we

413 decided to remove them. The model was not overdispersed (dispersion parameter $=0.470)$, and

414 collinearity was no issue (maximum VIF =1.014). We dropped taxon and the number of

415 potential partners from the fixed effects to obtain the null model. The samples for both models

416 comprised 178 individuals of 21 groups from 11 species.

417

$418 \quad$ Is allopreening associated with other affiliative social behaviors in corvids and parrots? (Models

$419 \underline{3 a \text { and } 3 b)}$

420 In order to test whether allopreening in parrots and corvids is positively related to other

421 affiliative behaviors, such as frequent close proximity and active feeding, and negatively

422 associated with agonistic interactions we ran two GLMMs. For each group, we looked at each 
423 focal bird's dyadic interactions with all other birds in the group. First, due to the differences in

424 definition of allopreening bouts and sampling methods across our diverse data sets, we

425 constructed binary categorical variables $(\mathrm{Y} / \mathrm{N})$ indicating whether the focal bird had: preened a

426 partner, actively fed a partner, or directed aggression towards a partner. Dyadic proximity scores

427 were calculated by dividing the total number of scans the focal bird had with the dyad partner as

428 their nearest neighbor, by the total number of proximity scans available for the focal bird. In the

429 first GLMM we investigated what social behaviors were associated with the occurrence of

430 allopreening within a dyad. Since the response was binary (allopreening absent or present) we

431 fitted the model with binomial error structure and logit link function. As fixed effects we

432 included the presence of active feeding (no or yes) and agonistic interactions (no or yes) and also

433 a dyadic proximity score. As random intercept effects we included the ID of the subject, the

434 partner, the group, and also species. We included random slopes of agonistic interactions and the

435 proximity score into all four random effects, and a random slope of active feeding within group

436 ID and species. Originally, we also included parameters for correlations among random

437 intercepts and slopes. However, as all of the absolute correlation parameters for partner ID,

438 group ID, and species were essentially one or unidentifiable ('not a number') we removed them

439 from the model (log-likelihoods, model with all correlation parameters: -166.43 ; model with no

440 correlation parameters: -171.225). The sample for this model comprised a total of 1,222 dyads

441 (only 86 engaged in preening) from 77 subjects with 90 partners in seven groups from six

442 species.

As there was a large number of birds for which agonistic data were not collected (or

444 emitters and receivers not identified), we fitted a second GLMM (Model 3b) excluding the

445 predictor presence of agonistic behaviors, which allowed us to test whether proximity or active 
446 feeding affected the likelihood of focal birds preening partners, using a larger sample size. This 447 was important to test whether patterns identified in Model 3a would generalize to a broader 448 sample of birds. Model 3b was identical to Model 3a with the exception that it lacked the fixed 449 effects and random slopes of presence of agonistic interactions. The sample for this model 450 consisted of a total of 1606 dyads (128 of which engaged in grooming) from 118 subjects with

451131 partners in 11 groups from nine species. Furthermore, several of the correlation parameters 452 among random intercepts and slopes in Model $3 \mathrm{~b}$ appeared unidentifiable, and we removed them 453 from the model (log-likelihoods; full model: -240.888; model with only the correlation 454 parameters within subject left: -245.399).

In the data sets for both models we z-transformed the proximity score to a mean of zero

456 and a standard deviation of one to ease model convergence and we also manually dummy coded 457 and then centered factors entering random slopes. In both models we included an offset term 458 (McCullagh \& Nelder, 1989) to control for varying dyadic observation times (log of observation 459 time in hours). In the case of both models, the null model lacked the fixed effects of presence of 460 active feeding and the dyadic proximity score, and for Model 3a the null model also lacked the 461 fixed effect of agonistic interactions. Collinearity was no issue in either of the two models 462 (maximum VIF, Model 3a: 1.352; Model 3b:1.317). Does head preening have a special value? (Models 4a and 4b)

Lastly, we examined the body part preened to determine whether head/neck preening was 466 more valuable than body preening and indicative of stronger social bonds within a dyad. For blue 467 and gold macaws, blue-throated macaws (two groups), great-green macaws (two groups), 468 common ravens, orange-winged amazon, greater vasa, and New Caledonian crows, data on the 
469 body part groomed were available. For these birds, we determined the proportion of preening the 470 focal birds directed to their partners' heads. To estimate the extent to which different factors

471 influenced the probability of allopreening another individual's head (Model 4a) and body (Model

4724 b) we focused on the three species with body part and social data available (blue and gold

473 macaw, orange winged Amazon, and vasa). We fitted two separate GLMMs with binomial error

474 structures and logit link functions (originally, we considered using a multinomial model, but 475 since it was common that in a given dyad preening of the head and the body was observed this 476 was not a viable option). Both models included the presence of active feeding (no or yes) in a 477 given dyad and the dyadic proximity score as key fixed effects. To control for their potential 478 differences, we further included species (factor with levels blue and gold macaw, orange winged 479 Amazon, and vasa) as a fixed effect. We included random intercept effects for subject ID and 480 partner ID and a random slope of proximity within both of them. As with the other models we 481 had originally included parameters for the correlation between random intercept and slope, but, 482 as these appeared unidentifiable, we removed them from both models. We dropped presence of 483 active feeding and the dyadic proximity score from the full models to obtain the null models. To 484 control for observation effort varying among dyads we included it as an offset term (log of 485 observation hours). Prior to fitting the models, we z-transformed the proximity score to a mean 486 of zero and a standard deviation of one to ease model convergence. Collinearity was no issue in 487 either of the two models (maximum squared Generalized VIF, after taking it to the power of $4881 /($ twice its degrees of freedom) (Fox \& Monette, 1992), Model 4a: 1.186; Model 4b: 1.186). The 489 sample for both models comprised a total of 392 dyads of 37 subjects with 45 partners in three 490 groups from three species. Head preening happened in 45 dyads and body preening in 31 dyads. 491 
493 We examined relative rates of mutual allopreening on three species for which these data were 494 available (orange-winged Amazon parrots, blue and gold macaws, and New Caledonian crows).

495 For this analysis, we only considered dyads that showed instances of allopreening (mutual or 496 unidirectional). We then assessed the proportion of allopreening that was mutual, and whether 497 this differed across the three species. The data we used for this assessment differed from the 498 allopreening bout data we used for the analyses described above. To consider the role of mutual 499 grooming, we examined the focal bird's role in preening behaviors and used the role to define 500 three types of grooming event: Give preening event, receive preening event or mutual preening 501 event. Each preening bout could contain multiple events. We calculated the proportion of mutual 502 grooming as the total number of mutual allopreening events for each dyad (i.e., number of 503 mutual allopreening events where A and B were mutually preening each other, with either A or 504 B being the focal bird) divided by total number of allopreening events involving A and B, 505 regardless of focal roles. Due to small sample sizes, a Mann Whitney U test was run to determine 506 whether there were significant differences in mutual allopreening proportion between blue and 507 gold macaws $(N=9)$ and orange-winged Amazon parrots $(N=16)$ (crows were excluded from 508 this analysis because they did not demonstrate mutual allopreening). The data lacked 509 independence due to individuals involved in multiple dyads. Thus, we randomly sampled the 510 data from dyads 1,000 times such that each individual was present at most once and averaged 511 results. The number of dyads retained ranged from nine to twelve and the minimum number 512 dyads per species was four. We then used an exact (Mundry \& Fischer, 1998) Mann-Whitney U513 test (Siegel \& Castellan, 1988) to compare the proportion of mutual preening between the two 514 species. 
Implementation of GLMMs and general considerations

517 We fitted the GLMMs in R (version 3.6.1; R Core Team, 2019) using the functions glmmTMB

518 of the identically named package (version 0.2.3; Brooks et al., 2017; models with beta error

519 distribution) or glmer of the package lme4 (version 1.1-21; Bates et al., 2015; models with other

520 error distributions). We compared full and null models utilizing likelihood ratio tests (Dobson,

521 2002), and obtained significance tests of individual fixed effects by dropping them from the

522 model one at a time and comparing model fits using likelihood ratio tests as well (Barr et al.,

523 2013). For all models we determined model stability by removing the levels of the random

524 effects one at a time and then comparing the estimates derived for the respective subsets of data

525 with those obtained for the complete data set. This revealed Model 1a, 1b, 1c, $2 \mathrm{a}$, and $2 \mathrm{~b}$ to be of

526 good and Model 3a, 3b, 4a, and 4b of moderate to poor stability (see results for details). We

527 determined confidence intervals of model estimates and fitted models using a parametric

528 bootstrap $(N=1,000)$ implemented with the functions simulate (package glmmTMB; models

529 with beta error distribution) or bootMer (package lme4; models with other error distribution). We

530 determined VIF or Generalized VIF (Fox \& Monette, 1992) using the function vif of the package

531 car (version 3.0-3; Fox \& Weisberg, 2011), applied to models lacking the random effects. We

532 report odds ratios which indicate how much the odds of observing a positive response changes

533 when a predictor increases by one unit.

534

535 Results

$536 \quad$ Comparison of social grooming in birds and Pan species

537 Proportion of time dedicated to social grooming in corvids, parrots and Pan species (Models 1a, $538 \quad 1 b$ and $1 c)$ 
539 The results of the three GLMMs showed that while rates of social grooming initiations (total

540 number of grooming bouts/observation time) in Pan species and birds were not significantly

541 different (Model 1c, Table 2), on average, corvids and parrots devoted a smaller proportion of

542 their time to social grooming than Pan species (total duration of grooming bouts/total

543 observation time; Model 1a; Table 2; Fig. 1a:). They also tended to socially groom in a smaller

544 proportion of scans (Model 1b; Table 2; Fig. 1b). Descriptives can be seen in Table 3.

545

$546 \quad$ Number of grooming interaction partners in corvids, parrots and Pan species (Models $2 a$ and

$547 \quad 2 b)$

548 Individual animals from both taxa groomed a similar proportion of their group members (Model

549 2a; Table 4; see Table 5 for descriptive statistics). However, when controlling for the number of

550 potential interaction partners, we found that, first, the number of actual interaction partners

551 clearly increased with the number of potential partners, and, second, that parrots and corvids

552 tended to have fewer grooming interaction partners than Pan species (Model 2b; Table 4; Fig. 2).

553 Descriptive statistics for adult and mixed-age groups included in these inferential analyses and

554 for juvenile groups are indicated in Table 6.

555

$556 \quad$ Is allopreening associated with other affiliative social behaviors in corvids and parrots? (Models

$557 \quad 3 a$ and $3 b)$

558 Allopreening was influenced by the three test predictors in Model 3a (proximity, presence of

559 active feeding and agonistic interactions; full null model comparison: $\chi^{2}=7.61, \mathrm{df}=3, P=$

560 0.055) and also by the two test predictors in Model $3 \mathrm{~b}$ (proximity and presence of active feeding;

$\left.561 \chi^{2}=14.04, \mathrm{df}=2, P=0.001\right)$. When individual predictors within each model were considered, 
562 however, both models revealed that only proximity explained a significant amount of variation in

563 the probability of allopreening to occur. The probability of allopreening being observed in a

564 given dyad clearly increased with its proximity score (Table 7; Fig. 3). This is unlikely to be

565 driven by sampling proximity when grooming was occurring (when close proximity is required),

566 as grooming occupied a very small proportion of the time budget: Four of six species included in

567 Model 3a and six of nine species included in Model 3b had duration of allopreening data

568 available; mean percentage of observation time these species spent allopreening was $2.63 \%$ and

$569 \quad 2.30 \%$, respectively.

570

571 Does head preening have a special value? (Models $4 a$ and $4 b$ )

572 We found no obvious association between the occurrence of head preening and the anatomical

573 preening mechanism (uropygial gland or powder down; Table 8). Across species with data on

574 region preened $(N=7)$, half or more of preening was directed to partners' heads (Table 8).

575 GLMMs run on a subset of these species (blue and gold macaw, orange-winged Amazon, greater

576 vasa) for whom all variables of interest were available, indicated that birds were selective in

577 whom they directed head preening towards. Both head and body preening were clearly

578 influenced by at least some of the test predictors in the model (active feeding and proximity; full

579 versus null model comparisons: head preening: $\chi^{2}=57.938, \mathrm{df}=2, \mathrm{p}<0.001$; body preening: $\chi^{2}$

$580=33.951, \mathrm{df}=2, \mathrm{p}<0.001)$. More specifically, head preening was significantly more common in

581 the orange-winged Amazons compared to the vasas, significantly more common in dyads in

582 which we observed active feeding, and also significantly more common in dyads with a larger

583 proximity score (Model 4a; Fig. 4a, b; Table 9). Body preening was not explicitly correlated with 
584 the dyadic presence of active feeding and did not differ between species, but it clearly increased

585 with increased dyadic proximity (Model 4b; Fig. 4c; Table 9).

$587 \quad$ Mutual allopreening

588 We compared frequency of mutual allopreening in three species for which these data were

589 available. Of dyads that engaged in allopreening, $89 \%$ of blue and gold macaw dyads $(N=9)$ and

$59031 \%$ of orange-winged Amazon dyads $(N=16)$ engaged in mutual allopreening. No crow dyad

$591(N=2)$ was observed mutually preening. The average result across the 1,000 random selections

592 of dyads revealed a significant species effect $(U=2.264, P=0.043)$, indicating that the

593 proportion of total allopreening that was mutual was significantly higher in macaws $(M d n=.22$,

$594 N=8)$ compared to Amazons $(M d n=.02, N=10)$. Further statistical testing of whether mutual

595 preening is a particularly valuable type of grooming, indicative of strong social bonding was not

596 possible due to the low sample size. However, descriptively, dyads that mutually preened had

597 higher proximity scores $(M=.55, S D=.26)$ compared to dyads that were allopreening partners

598 but did not mutually preen $(M=.18, S D=.14)$.

599

600

601

602

603

604

605

606

607

\section{Discussion}

Although inter-species variation was found in rates of allopreening initiations and proportion of time invested in this activity, allopreening was observed in all parrot and corvid species in this study. This is consistent with findings from Kenny et al.'s (2017) comparative analyses, which indicate that allopreening most commonly occurs in species that engage in bi-parental care of offspring and show pair bond stability across breeding seasons. These avian partnerships share key similarities with chimpanzee and bonobo alliances; namely, their cooperative and stable nature (often persisting across years, Clayton \& Emery, 2007; Emery et al., 2007; Forshaw, 
2006; Seibert, 2006). For Pan species and corvids/parrots, the quality and effectiveness of these partnerships have substantial fitness implications (De Waal, 1995; Hoppe, 1992; Kaburu et al., 2013; Mitani, 2009; Røskaft, 1983; Spoon, 2006; Spoon et al., 2006, 2007; Wilson et al., 1995).

These similarities, along with associations between social grooming and relationship quality/stability that previous studies have found (Fraser \& Bugnyar, 2010; Gill, 2012; Kenny et al., 2017; Spoon et al., 2006, 2007), suggest that bond strength may be similarly maintained through social grooming in parrot/corvid pair bonds and chimpanzee/bonobo alliances. Our analyses revealed that parrots/corvids and bonobos/chimpanzees initiated social grooming bouts at similar rates; however, Pan species demonstrated significantly higher levels of investment in social grooming than parrots and corvids in terms of the duration spent engaged in grooming. Pan species also tended to groom with a higher proportion of their group members when controlling for group size, than corvids and parrots. The implications of these cross-taxon comparisons are constrained both by the focus on Pan species, rather than a wide range of primate species and the focus on captive animals. Unfortunately, due to a lack of data on wild parrot and corvid behavior, the effect of captivity on behavior, and particularly social grooming, cannot be quantified and may therefore be different for each species included in our study. This may have added noise to our data and/or biased our results. Whilst keeping these caveats in mind, one potential explanation for the pattern of results we found is that chimpanzees and bonobos have more affiliative relationships to maintain than parrots and corvids which requires a greater investment of overall grooming time. This is in line with the suggestion that primates form strong affiliative bonds with multiple individuals, that are similar in nature to reproductive pair bonds in other taxa (Dunbar \& Shultz, 2007). Maintaining multiple strong affiliative relationships through social grooming may be more important for Pan species than most parrots 
631 and corvids due to differences in mating behavior (promiscuous mating vs monogamy; e.g.

632 Seibert, 2006; Stanford, 1998), the degree of fission-fusion dynamics (time separated from

633 important social partners is high vs low; e.g. Aureli et al., 2008; Clayton \& Emery, 2007;

634 Boucherie et al., 2019) and the linearity of the dominance hierarchy (the utility of alliances to

635 climb the hierarchy and to protect from severe physical aggression from higher ranking

636 individuals is high vs low; e.g. Baker \& Aureli, 2000; Terry, 1970). Future research should

637 include a greater diversity of primate species and investigate whether the proportion of time

638 investment in grooming per dyadic relationship is similar between taxa, in order to distinguish

639 between the possibilities that Pan species require more time grooming to maintain multiple

640 relationships or to create stronger bonds than are necessary in birds. In particular, data from

641 primarily monogamous primates such as gibbons or titi monkeys may be valuable to address this

642 question.

643 Despite most parrot and corvid species included in our analyses having a monogamous

644 mating system, approximately half of the birds we observed had two or more preening partners,

645 with some birds having as many as five in just a 240-minute period of observation. Although

646 distributed grooming effort might be expected in immature birds, the majority of our groups

$647(16 / 24)$ contained only adult birds, so this was an unexpected finding. Although extra-pair

648 affiliative relationships have been documented in parrot and corvids, these relationships tend to

649 be less stable, and relationships between reproductive partners appear to have the greatest fitness

650 implications (Boucherie et al., 2016; Clayton \& Emery, 2007; Garnetzke-Stollmann et al., 1991;

651 Spoon et al., 2006, 2007). This finding may support a growing body of evidence suggesting that

652 extra-pair affiliations are much more common among socially monogamous birds than

653 previously thought (Boucherie et al., 2016; Griffith et al., 2002; Spoon et al., 2002); based on 
654 genetic analyses. For instance, it has been estimated that approximately $11 \%$ of offspring are the

655 product of extra-pair copulation in species identified as socially monogamous (Griffith et al.,

656 2002). Alternatively, aspects of the captive environment may have also contributed to the

657 provision of grooming to multiple partners observed in our birds, just as it may have done in the

658 Pan species. In the birds, being confined in a cage with other pair bonded animals may also

659 produce dynamics similar to those found in colonial species, where allopreening occurs between

660 neighboring pairs with the apparent function of reducing aggression between them (Lewis et al.,

661 2007), or in large wild aggregations, where grooming of unrelated non-mates can occur

662 (Harrison, 1965). The persistent close contact with multiple individuals may also increase the

663 likelihood of assessing other potential mates. As species' behavior may have been affected in a

664 variety of ways by captivity, it is unclear whether similar patterns as those observed in our study

665 would be found if social grooming of wild individuals of the same species were investigated.

666 In terms of assessing whether allopreening was associated with other affiliative behaviors,

667 and may therefore be part of a suite of behaviors used to maintain affiliative relationships with

668 important social partners, we found support for allopreening being provided selectively within a

669 group, with focal birds more likely to preen a dyad partner that they were often in close proximity

670 to. Our findings are consistent with previous studies of captive and wild birds which have provided

671 substantial evidence indicating that parrots and corvids demonstrate spatial organization and

672 association patterns that are not random, with individuals showing a high degree of consistency in

673 with whom they maintain close physical proximity to and interact with (Boucherie et al., 2016;

674 Emery et al., 2007; Forshaw, 2006; Fraser \& Bugnyar, 2010; Garnetzke-Stollmann \& Franck,

675 1991; Pitter \& Christiansen, 1997; Seibert \& Crowell-Davis, 2001; Seibert, 2006; Spoon et al.,

676 2006, 2007; Wechsler, 1989). Our findings are also consistent with studies of mammalian species, 
677 which identified positive correlations between allogrooming and proximity measures. For 678 instance, associations between these two factors are widely found in a range of primates (e.g., 679 chimpanzees, Langergraber et al., 2009; bonobos, Tokuyama \& Furuichi, 2016; gibbons, Palombit, 680 1996; java monkeys, pigtail macaques, Troisi et al., 1989). Outside the primate order, Sato and 681 colleagues (1993) found a positive correlation between allogrooming duration while housed and 682 maintenance of physical proximity while out at pasture in cows. Importantly, the maintenance of 683 close physical proximity is also predictive of long-term bond stability in a number of species (e.g., 684 Black, 2001; Garroway \& Broders, 2007; Gilby \& Wrangham, 2008; Koski et al. 2012; Massen \& 685 Sterck 2013; Moller, et al., 2001; Silk et al., 2006; Zabel et al., 1992). It seems that parrots and 686 corvids are selective in whom they maintain close physical proximity to and are more likely to 687 engage in allopreening with these individuals, who likely represent important social partners. 689 requires close physical proximity, if individuals were preening as a proximity scan was taken, they 690 would be recorded as nearest neighbors, which might offer a simple explanation for this 691 relationship. Unfortunately, we were unable to identify and exclude proximity scans taken whilst 692 birds were preening from our analysis as the behavioral context of the animal at the time of each 693 scan was not recorded in the majority of our groups. However, we estimate (from study groups 694 that had duration of allopreening data available in each model) that on average the birds in our 695 models only spent approximately $2.63 \%$ (based on four of six species included in Model 3a) and $6962.30 \%$ (based on six of nine species included in Model 3b) of their observation time engaged in 697 preening. It therefore seems unlikely that a sufficient number of proximity scans would have 698 coincided with preening to be responsible for this effect. It is also possible that the variation in 699 bird density within an aviary and the proximity criteria used to identify nearest neighbors in each 
700 species (see Table 1, Table S1) may have influenced the relationship between proximity and 701 allopreening. It is thus vital that future studies are conducted, where data collection methods are 702 agreed in advance with a broad range of species to understand the relationship between proximity 703 and allopreening in more depth. Future investigations would also benefit from longitudinal 704 analyses, examining how measures of relationship quality, including proximity, predict variation 705 in allopreening interactions over time. While cross-sectional correlational analyses such as the 706 ones we report in the present paper do not allow for the determination of whether associations 707 between allopreening and social factors are causal in nature, further in-depth investigations would 708 contribute to our understanding of how allopreening may be used to manage relationships and help 709 clarify the directionality of associations.

710 We predicted that allopreening would be negatively correlated with agonistic behavior, 711 however we found no evidence for such a relationship. Subjects were not less likely to preen 712 individuals they had directed aggression towards than those they had not. While it is not clear why 713 no such relationship was found, it is possible that parrots and corvids are simply less likely to 714 directly interact with individuals that they do not have affiliative relationships with, compared to 715 those they do have affiliative relationships with. If so, there may be less opportunity to enter into 716 conflicts with individuals outside the pair bond. Additionally, limitations of our analysis may have 717 reduced our ability to observe a significant correlation between these two factors. Due to 718 differences in sampling methods and behavioral definitions across our diverse data set, we used 719 binary measures for social behaviors (e.g., did subjects direct aggression towards partners? Y/N). 720 Assessing potential associations between social behaviors using categorical variables, as opposed 721 to rates, for example, may have limited the detection of more subtle variation dyads may have 722 demonstrated on these social measures. Our analyses were also solely focused on aggressive 
723 behavior and preening that was directed to partners by focal birds. It would be valuable to also

724 investigate whether preening a partner is predicted by being the recipient of aggression emitted by

725 a partner. If such a relationship were found, it would suggest that allopreening may be used as a

726 strategy for reducing or avoiding aggression, as has been found in ravens (Fraser \& Bugnyar, 727 2011).

728

729

730

731

732

733

734

735

736

737

738

739

740

741

742

743

744

745

In contrast to our predictions, active feeding was not a significant predictor of allopreening occurrence in either of our main models. There are several reasons that may explain this unexpected pattern of results. First, this may partly be due to the rare occurrence of active feeding in our study groups (occurring in just 34 of 1222 dyads in Model 3a and in 57 of 1606 dyads in Model 3b). It was not observed at all in three of the nine species included in our analyses (Goffin's cockatoo, orange-winged Amazon, New Caledonian crow). Second, as active feeding, and in particular allofeeding, has been most widely found to occur between parent and offspring and between reproductive partners during breeding seasons, our findings may be explained by the fact that most of the groups included in our analyses did not include breeding pairs (see Table 1). Third, it is possible that the type of active feeding individuals engage in may have particular significance. In our study, the behavioral category of active feeding combined the transfer of monopolizable food items and regurgitation into the mouth. The latter is a more physically intimate act and may occur in a more affiliative context than the transfer of a food item, which may be more likely to occur in situations where the donor may be motivated by harassment avoidance (e.g. De Kort et al., 2006). It is, however, also possible that allofeeding may be more instinctually driven, and may be triggered by others engaging in submissive or begging behaviors that reliably elicit allofeeding when performed by juveniles or reproductive partners (Ellis et al., 2009; Wright, 1998). Assessing whether functional differences exist between these types of active feeding, and between active 
746 feeding that occurs within and outside the breeding context, are avenues of research worth pursuing

747 as they may provide deeper insight into the mechanisms avian species use to manage their social

748 relationships. Finally, it could also be that allofeeding is selectively performed with the most

749 valuable partners, and by considering preening of any body region in the main models we may

750 have overlooked the predictive value of allofeeding. In our analyses focusing on blue-throated

751 macaws, orange-winged Amazons and vasas (Models 4a; 4b), we found that birds who engaged in

752 allofeeding were more likely to engage in allopreening of their partner's head, but not their body.

753 Ectoparasitic infestations tend to be higher in the head since it cannot be autopreened (Boyd, 1951;

754 Cox, 2012). Thus, head preening, as opposed to body preening, may make a greater contribution

755 to an individual's fitness due to its hygienic benefits and thus be of higher value and conferred

756 only on the most valuable partners. It is also possible that individuals may be more willing to

757 receive head preening from partners they have a strong, valued relationship with, and therefore

758 trust; allowing a conspecific to preen the head, particularly around the eyes, carries risk of injury

759 that could negatively affect long-term survival. Taken together it seems that head-preening and

760 allofeeding may be markers of a strong and valued relationship in parrots and corvids, but future

761 research needs to confirm this in a wider range of species.

762

In our exploratory investigation of mutual preening, we found significant differences in

763 how frequently it occurred in the three species for which these data were available. While it was

764 not observed at all in New Caledonian crows, it was found to occur in blue and gold macaws and

765 orange-winged Amazons, with macaws showing significantly higher proportions of mutual

766 preening as compared to Amazons. Although we did not have data on mutual preening for a

767 sufficient number of groups to carry out an analysis of its potential functions, we found that for

768 dyads that engaged in allopreening, mean proximity scores were higher for those that mutually 
769 preened as compared to those that did not. Future research should investigate this potential 770 relationship further in a broad number of species, as mutual grooming may be an important 771 indicator of bond strength. Further investigation is also needed to determine whether inter-species 772 variation in whether mutual preening occurs or not may be better explained by social factors (e.g.

773 bond strength) or anatomical differences (e.g., neck length, bill morphology), that may make it 774 easier for one species to engage in this behavior than another.

775 In conclusion, allopreening seems to serve an important social function in corvids and 776 parrots. These birds are selective with whom they maintain regular close proximity with and they 777 are more likely to engage in allopreening with these specific social partners, indicating that both 778 frequent close physical proximity and allopreening are markers of affiliative social bonds. Head 779 preening and mutual preening should be investigated in a wider range of species to confirm 780 whether these types of allopreening are markers of particularly strong and valuable relationships. 781 Corvids and parrots, in comparison to Pan species, tend to socially groom a smaller proportion 782 of their group members, and this may explain the reduced time birds dedicate to social grooming 783 compared to chimpanzees and bonobos.

\section{References}

Abbassi, P., \& Burley, N. T. (2012). Nice guys finish last: same-sex sexual behavior and pairing success in male budgerigars. Behavioral Ecology, 23, 775-782. doi.org/10.1093/beheco/ars030 85, 559-568. 
Aureli, F., Preston, S. D., \& de Waal, F. (1999). Heart rate responses to social interactions in free-moving rhesus macaques (Macaca mulatta): a pilot study. Journal of Comparative Psychology, 113, 59.

Aureli, F., \& Schaffner, C. M. (2007). Aggression and conflict management at fusion in spider monkeys. Biology Letters, 3, 147-149. doi:10.1098/rsb1.2007.0041

Aureli F., Schaffner C.M., Boesch C., Bearder S.K., Call J., Chapman C.A., Connor R., Di Fiore A., Dunbar R.I.M., Henzi S.P., Holekamp K., Korstjens A.H., Layton R., Lee P., Lehmann J., Manson J.H., Ramos-Fernandez G., Strier K.B., Van Schaik C.P. (2008). Fission-fusion dynamics: New research frameworks. Current Anthropology 49, 627654. doi: $10.1086 / 586708$

Baayen, R.H. (2008). Analyzing Linguistic Data. Cambridge University Press. Cambridge

Baker, K. C., \& Aureli, F. (2000). Coping with conflict during initial encounters in chimpanzees. Ethology, 106, 527-541. doi: 10.1111/j.1439-0310.2000.00553.

Barr, D. J., Levy, R., Scheepers, C., \& Tily, H. J. (2013). Random effects structure for confirmatory hypothesis testing: Keep it maximal. Journal of Memory and Language, 68(3), 255-278. doi:10.1016/j.jml.2012.11.001

Barrett, L., Henzi, S. P., Weingrill, T., Lycett, J. E., \& Hill, R. A. (1999). Market forces predict grooming reciprocity in female baboons. Proceedings of the Royal Society of London. Series B: Biological Sciences, 266, 665-670.

Bates, B., Maechler, M., Bolker, B., \& Walker, S. (2015). Fitting linear mixed-effects models usinglme4. Journal of Statistical Software, 67, 1-48.

Berghänel, A., Ostner, J., Schröder, U., \& Schülke, O. (2011). Social bonds predict future cooperation in male Barbary macaques, Macaca sylvanus. Animal Behaviour, 81, 11091116. doi: 10.1016/j.anbehav.2011.02.009

Black, J. M. (Ed.). (1996). Partnerships in birds: The study of Monogamy: The Study of 
Monogamy. Oxford University Press, UK.

819

820

821

822

823

824

825

826

827

828

829

830

831

832

833

834

835

836

837

838

839

840

Black, J. M. (2001). Fitness consequences of long-term pair bonds in barnacle geese: monogamy in the extreme. Behavioral Ecology, 12, 640-645. doi: 10.1093/beheco/12.5.640

Bolker, B. M. (2008). Ecological Models and Data in R. Princeton University Press.

Boucherie, P. H., Loretto, M. C., Massen, J. J., \& Bugnyar, T. (2019). What constitutes "social complexity" and "social intelligence" in birds? Lessons from ravens. Behavioral Ecology and Sociobiology, 73, 12.

Boucherie, P. H., Mariette, M. M., Bret, C., \& Dufour, V. (2016). Bonding beyond the pair in a monogamous bird: impact on social structure in adult rooks (Corvus frugilegus). Behaviour, 153, 897-925. doi: 10.1163/1568539X-00003372

Boyd, E. M. (1951). The external parasites of birds: a review. The Wilson Bulletin, 63, 363369.

Bräger, S., Würsig, B., Acevedo, A., \& Henningsen, T. (1994). Association patterns of bottlenose dolphins (Tursiops truncatus) in Galveston Bay, Texas. Journal of Mammalogy, 75, 431-437. doi: 10.2307/1382564

Braun, A., \& Bugnyar, T. (2012). Social bonds and rank acquisition in raven nonbreeder aggregations. Animal Behaviour, 84(6), 1507-1515.

Brooke, M. D. L. (1985). The effect of allopreening on tick burdens of molting eudyptid penguins. The Auk, 893-895.

Brooks, M. E., Kristensen, K., van Benthem, K. J., Magnusson, A., Berg, C. W., Nielsen, A., Skaug, H. J., Maechler, M., \& Bolker, B. M. (2017). glmmTMB balances speed and flexibility among packages for zero-inflated generalized linear mixed modeling. The $R$ Journal, 9(2), 378-400. 
841 Carter, G., \& Leffer, L. (2015). Social grooming in bats: are vampire bats exceptional?. PLoS $842 \quad$ One, 10, e0138430. doi:10.1371/journal.pone.0138430

843 Call, J., Judge, P. G., \& de Waal, F. B. (1996). Influence of kinship and spatial density on 844 reconciliation and grooming in rhesus monkeys. American Journal of Primatology, 39, 845 846 847 848 849 35-45. doi:10.1002/(SICI)1098-2345(1996)39:1<35::AID-AJP3>3.0.CO;2-T

Christian, S. (2000). What Could Be Greater than the Greater Vasa Parrot? (Coracopsis vasa). AFA Watchbird, 27, 54-57.

Clayton, N. S., \& Emery, N. J. (2007). The social life of corvids. Current Biology, 17, R652R656.

Clayton, D. H., Koop, J. A., Harbison, C. W., Moyer, B. R., \& Bush, S. E. (2010). How birds combat ectoparasites. Open Ornithol. J, 3, 41-71.

852 Cooper, M. A., \& Bernstein, I. S. (2000). Social grooming in Assamese macaques (Macaca 853 854 assamensis). American Journal of Primatology, 50, 77-85. doi: 10.1002/(SICI)10982345(200001)50:1<77::AID-AJP7>3.0.CO;2-R

Cox, J. A. (2012). Social grooming in the Brown-headed Nuthatch may have expanded functions. Southeastern Naturalist, 11, 771-775. doi: 10.1656/058.011.0415

De Kort, S. R., Emery, N. J., \& Clayton, N. S. (2006). Food sharing in jackdaws, Corvus monedula: what, why and with whom?. Animal Behaviour, 72, 297-304. doi: 10.1016/j.anbehav.2005.10.016

De Waal, F. B. (1995). Bonobo sex and society. Scientific American, 272, 82-88. De Waal, F. B. (1997). The chimpanzee's service economy: food for grooming. Evolution and Human Behavior, 18, 375-386.

di Bitetti, M. S. (1997). Evidence for an important social role of allogrooming in a platyrrhine primate. Animal Behaviour, 54, 199-211. doi: 10.1006/anbe.1996.0416 
Dobson AJ. (2002). An Introduction to Generalized Linear Models. Chapman \& Hall/CRC. Boca

Raton .Dunbar, R. I. (1991). Functional significance of social grooming in primates. Folia Primatologica, 57, 121-131. doi: 10.1159/000156574

Dunbar, R. I., \& Shultz, S. (2007). Evolution in the social brain. Science, 317, 1344-1347. doi: 10.1126/science. 1145463

Dunbar, R. I., \& Shultz, S. (2010). Bondedness and sociality. Behaviour, 775-803.

Duque, J. F., \& Stevens, J. R. (2016). Voluntary food sharing in pinyon jays: the role of reciprocity and dominance. Animal Behaviour, 122, 135-144.

Elder, W. H. (1954). The oil gland of birds. The Wilson Bulletin, 66(1), 6-31.

Ellis, J. M., Langen, T. A., \& Berg, E. C. (2009). Signalling for food and sex? Begging by reproductive female white-throated magpie-jays. Animal Behaviour, 78, 615-623. doi: 10.1016/j.anbehav.2009.05.024

Emery, N. J. \& Clayton, N. S. (2004). The mentality of crows: convergent evolution of intelligence in corvids and apes. Science, 306, 1903-1907. doi: 10.1126/science.1098410

Emery, N. J., Seed, A. M., Von Bayern, A. M., \& Clayton, N. S. (2007). Cognitive adaptations of social bonding in birds. Philosophical Transactions of the Royal Society B: Biological Sciences, 362, 489-505. doi: doi.org/10.1098/rstb.2006.1991

Erickson, C. J. (1973). Mate familiarity and the reproductive behavior of ringed turtle doves. The Auk, 90, 780-795.

Fedurek, P., Dunbar, R. I., \& British Academy Centenary Research Project. (2009). What does mutual grooming tell us about why chimpanzees groom? Ethology, 115, 566-575. doi : 10.1111/j.1439-0310.2009.01637.x

Feh, C., \& de Mazières, J. (1993). Grooming at a preferred site reduces heart rate in 
horses. Animal Behaviour, 46, 1191-1194. doi: 10.1006/anbe.1993.1309

889

890

891

892

893

894

895

896

897

898

899

900

901

902

903

904

905

906

907

908

909

910

911

Forshaw, J.M. (2006). Parrots of the World. Princeton, NJ: Princeton University Press.

Forsman, E. D., \& Wight, H. M. (1979). Allopreening in Owls: What Are Its Functions? The Auk, 96, 525-531. doi: 10.1093/auk/96.3.525

Forstmeier, W., \& Schielzeth, H. (2011). Cryptic multiple hypotheses testing in linear models: overestimated effect sizes and the winner's curse. Behavioral Ecology and Sociobiology, 65(1), 47-55.

Fox, J. \& Monette, G. (1992). Generalized Collinearity Diagnostics. Journal of the American Statistical Association, 87, 178-183.

Fox J \& Weisberg S. (2011). An R Companion to Applied Regression, Second Edition. Thousand Oaks CA: Sage.

Franz, C. (1999). Allogrooming behavior and grooming site preferences in captive bonobos (Pan paniscus): association with female dominance. International Journal of Primatology, $20,525-546$.

Fraser, O. N., \& Bugnyar, T. (2010). The quality of social relationships in ravens. Animal Behaviour, 79, 927-933. doi: 10.1016/j.anbehav.2010.01.008

Fraser, O. N., \& Bugnyar, T. (2010b). Do ravens show consolation? Responses to distressed others. PLoS One, 5(5), e10605.

Fraser, O. N., \& Bugnyar, T. (2011). Ravens reconcile after aggressive conflicts with valuable partners. PLoS ONE, 6(3), e18118. doi.org/10.1371/journal.pone.0018118

Fraser, O. N., \& Bugnyar, T. (2012). Reciprocity of agonistic support in ravens. Animal Behaviour, 83, 171-177. doi: 10.1016/j.anbehav.2011.10.023

Fraser, O. N., Schino, G., \& Aureli, F. (2008). Components of relationship quality in chimpanzees. Ethology, 114, 834-843. doi: 10.1111/j.1439-0310.2008.01527.x 
912 Garnetzke-Stollmann, K., \& Franck, D. (1991). Socialisation tactics of the spectacled parrotlet

913

914

915

916

917

918

919

920

921

922

923

924

925

926

927

928

929

930

931

932

933

(Forpus conspicillatus). Behaviour, 119, 1-29. doi: 10.1163/156853991X00346

Garroway, C. J., \& Broders, H. G. (2007). Nonrandom association patterns at northern longeared bat maternity roosts. Canadian Journal of Zoology, 85, 956-964. doi: 10.1139/Z07079

Gilby, I. C., \& Wrangham, R. W. (2008). Association patterns among wild chimpanzees (Pan troglodytes schweinfurthii) reflect sex differences in cooperation. Behavioral Ecology and Sociobiology, 62, 1831.

Gill, S. A. (2012). Strategic use of allopreening in family-living wrens. Behavioral Ecology and Sociobiology, 66, 757-763.

Griffith, S. C., Owens, I. P., \& Thuman, K. A. (2002). Extra pair paternity in birds: a review of interspecific variation and adaptive function. Molecular Ecology, 11, 2195-2212. doi: 10.1046/j.1365-294X.2002.01613.x

Güntürkün, O., \& Bugnyar, T. (2016). Cognition without cortex. Trends in Cognitive Sciences, 20, 291-303. doi: 10.1016/j.tics.2016.02.001

Harrison, C. J. O. (1965). Allopreening as agonistic behaviour. Behaviour, 161-209.

Henazi, S. P., \& Barrett, L. (1999). The value of grooming to female primates. Primates, 40, 47-59.

Hoppe, D. (1992). The World of Amazon Parrots. Neptune City, New Jersey: T.F.H Publications, Inc.

Ju, S., \& Lee, S. I. (2016). Effect of kinship on the allopreening among juvenile Bengalese finches. Animal Cells and Systems, 20, 213-217. doi: 
935

936

937

938

939

940

941

942

943

944

945

946

947

948

949

950

951

952

953

954

955

956

Kaburu, S. S., Inoue, S., \& Newton-Fisher, N. E. (2013). Death of the alpha: withincommunity lethal violence among chimpanzees of the Mahale Mountains National Park. American Journal of Primatology, 75, 789-797. doi: 10.1002/ajp.22135

Kenny, E., Birkhead, T. R., \& Green, J. P. (2017). Allopreening in birds is associated with parental cooperation over offspring care and stable pair bonds across years. Behavioral Ecology, 28, 1142-1148. doi: 10.1093/beheco/arx078

Koski, S. E., de Vries, H., van de Kraats, A., \& Sterck, E. H. (2012). Stability and change of social relationship quality in captive chimpanzees (Pan troglodytes). International Journal of Primatology, 33, 905-921.

Koyama, N. F., Caws, C., \& Aureli, F. (2012). Supply and demand predict male grooming of swollen females in captive chimpanzees, Pan troglodytes. Animal Behaviour, 84, 1419-1425. doi: 10.1016/j.anbehav.2012.09.007

Kushlan, J. A. (2011). The terminology of courtship, nesting, feeding and maintenance in herons.

Kutsukake, N., \& Clutton-Brock, T. H. (2006). Social functions of allogrooming in cooperatively breeding meerkats. Animal Behaviour, 72, 1059-1068. doi: 10.1016/j.anbehav.2006.02.016

Lambert, M. L., Jacobs, I., Osvath, M., \& von Bayern, A. M. (2018). Birds of a feather? Parrot and corvid cognition compared. Behaviour, 1, 1-90. doi: 10.1163/1568539X-00003527

Langergraber, K., Mitani, J., \& Vigilant, L. (2009). Kinship and social bonds in female chimpanzees (Pan troglodytes). American Journal of Primatology: Official Journal of the American Society of Primatologists, 71, 840-851. doi: 10.1002/ajp.20711

Lewis, S., Roberts, G., Harris, M. P., Prigmore, C., \& Wanless, S. (2007). Fitness increases with 
partner and neighbour allopreening. Biology Letters, 3, 386-389.

doi:10.1098/rsbl.2007.0258

Massen, J. J., Overduin-de Vries, A. M., de Vos-Rouweler, A. J., Spruijt, B. M., Doxiadis, G. G., \& Sterck, E. H. (2012). Male mating tactics in captive rhesus macaques (Macaca mulatta): the influence of dominance, markets, and relationship quality. International Journal of Primatology, 33, 73-92. doi: 10.1007/s10764-011-9552-5

Massen, J. J., \& Sterck, E. H. (2013). Stability and durability of intra-and intersex social bonds of captive rhesus macaques (Macaca mulatta). International Journal of Primatology, 34, 770-791. doi: 10.1007/s10764-013-9695-7

Massen, J., Sterck, E., \& De Vos, H. (2010). Close social associations in animals and humans: functions and mechanisms of friendship. Behaviour, 147, 1379-1412. doi: $10.1163 / 000579510 X 528224$

Matuschek, H., Kliegl, R., Vasishth, S., Baayen, H., \& Bates, D. (2017). Balancing Type I error and power in linear mixed models. Journal of Memory and Language, 94, 305-315.

McCullagh, P. \& Nelder, J.A. (1989). Generalized Linear Models. Chapman and Hall. London.

Mitani, J. C. (2009). Male chimpanzees form enduring and equitable social bonds. Animal Behaviour, 77, 633-640. doi: 10.1016/j.anbehav.2008.11.021

Miyazawa, E., Seguchi, A., Takahashi, N., Motai, A., \& Izawa, E.-I. (in press) Different patterns of allopreening in the same-sex and opposite-sex interactions of juvenile large-billed crows (Corvus macrorhynchos). Ethology, this issue.

Möller, L. M., Beheregaray, L. B., Harcourt, R. G., \& Krützen, M. (2001). Alliance membership and kinship in wild male bottlenose dolphins (Tursiops aduncus) of southeastern Australia. Proceedings of the Royal Society of London. Series B: Biological 
Sciences, 268, 1941-1947. doi: 10.1098/rspb.2001.1756

981 Montalti, D., \& Salibián, A. (2000). Uropygial gland size and avian habitat. Ornitologia $982 \quad$ Neotropical, 11, 297-306.

983 Mooring, M. S. (1995). The effect of tick challenge on grooming rate by impala. Animal Behaviour, 50, 377-392. doi: 10.1006/anbe.1995.0253 samples often leads to incorrect P-values: Examples from Animal Behaviour. Animal Behaviour., 56, 256 - 259.

O'Brien, T. G. (1993). Allogrooming behaviour among adult female wedge-capped capuchin 989

monkeys. Animal Behaviour, 46, 499-510. doi: 10.1006/anbe.1993.1218

990

991

992

993

994

995

996

997

Mundry, R. \& Fischer, J. (1998). Use of statistical programs for nonparametric tests of small

Palombit, R. A. (1996). Pair bonds in monogamous apes: a comparison of the siamang Hylobates syndactylus and the white-handed gibbon Hylobates lar. Behaviour, 133, 321-356. doi: $10.1163 / 156853996 \times 00486$

Pitter, E., \& Christiansen, M. B. (1997). Behavior of individuals and social interactions of the red-fronted macaw Ara rubrogenys in the wild during the midday rest. Ornitologia Neotropical, 8, 133-143.

Poulin, R. (1991). Group-living and infestation by ectoparasites in passerines. The Condor, 93, 418-423. doi: 10.2307/1368958

Radford, A. N., \& Du Plessis, M. A. (2006). Dual function of allopreening in the cooperatively breeding green woodhoopoe, Phoeniculus purpureus. Behavioral Ecology and Sociobiology, 61, 221-230.

Renton, K. (2004). Agonistic interactions of nesting and nonbreeding macaws. The 
1003 1004

1005

1006

1007

1008

1009

1010

1011

1012

1013

1014

1015

1016

1017

1018

1019

1020

1021

1022

1023

1024

Rifkin, J. L., Nunn, C. L., \& Garamszegi, L. Z. (2012). Do animals living in larger groups experience greater parasitism? A meta-analysis. The American Naturalist, 180(1), 70-82. doi: $10.1086 / 666081$

Røskaft, E. (1983). Sex-role partitioning and parental care by the Rook Corvus frugilegus. Ornis Scandinavica, 180-187. doi: 10.2307/3676151

Schielzeth, H., \& Forstmeier, W. (2008). Conclusions beyond support: overconfident estimates in mixed models. Behavioral Ecology, 20(2), 416-420.

Schino, G. (2001). Grooming, competition and social rank among female primates: a metaanalysis. Animal Behaviour, 62, 265-271. doi: 10.1006/anbe.2001.1750

Schino, G. (2006). Grooming and agonistic support: a meta-analysis of primate reciprocal altruism. Behavioral Ecology, 18, 115-120. doi: 10.1093/beheco/ar1045

Schino, G., Scucchi, S., Maestripieri, D., \& Turillazzi, P. G. (1988). Allogrooming as a tensionreduction mechanism: a behavioral approach. American Journal of Primatology, 16, 4350. doi: 10.1002/ajp.1350160106

Seibert, L. M. (2006). Social behavior of psittacine birds. Manual of parrot behavior, 43-48.

Seibert, L. M., \& Crowell-Davis, S. L. (2001). Gender effects on aggression, dominance rank, and affiliative behaviors in a flock of captive adult cockatiels (Nymphicus hollandicus). Applied Animal Behaviour Science, 71, 155-170. doi: 10.1016/S01681591(00)00172-6

Seyfarth, R. M. (1977). A model of social grooming among adult female monkeys. Journal of Theoretical Biology, 65, 671-698. doi: 10.1016/0022-5193(77)90015-7

Seyfarth, R. M., \& Cheney, D. L. (1984). Grooming, alliances and reciprocal altruism in vervet 
monkeys. Nature, 308, 541.

Siegel, S. \& Castellan, N.J. (1988). Nonparametric Statistics for the Behavioral Sciences (2nd ed.). McGraw-Hill. New York.

Silk, J. B., Altmann, J., \& Alberts, S. C. (2006). Social relationships among adult female baboons (Papio Cynocephalus) I. Variation in the strength of social bonds. Behavioral Ecology and Sociobiology, 61, 183-195.

Sklepkovych, B. (1997). The influence of kinship on foraging competition in Siberian jays. Behavioral Ecology and Sociobiology, 40, 287-296. doi: 10.1007/s002650050344

Smith, S. M. (1980). Demand behavior: a new interpretation of courtship feeding. The Condor, 82, 291-295. doi: 10.2307/1367395

Spoon, T. R. (2006). Parrot reproductive behavior, or who associates, who mates, and who cares. Manual of Parrot Behavior, 63-77.

Spoon, T. R., Millam, J. R., \& Owings, D. H. (2006). The importance of mate behavioural compatibility in parenting and reproductive success by cockatiels, Nymphicus hollandicus. Animal Behaviour, 71, 315-326. doi: 10.1016/j.anbehav.2005.03.034

Spoon, T. R., Millam, J. R., \& Owings, D. H. (2007). Behavioural compatibility, extrapair copulation and mate switching in a socially monogamous parrot. Animal Behaviour, 73, 815-824. doi: 10.1016/j.anbehav.2006.10.010

Stanford, C. B. (1998). The social behavior of chimpanzees and bonobos: empirical evidence and shifting assumptions. Current Anthropology, 39, 399-420.

Stopka, P., \& Graciasová, R. (2001). Conditional allogrooming in the herb-field mouse. Behavioral Ecology, 12, 584-589. doi: 10.1093/beheco/12.5.584 
1047 Team, R. C. (2019). R: A Language and Environment for Statistical Computing, Version 3.3.

1048

1049

1050

1051

1052

1053

1054

1055

1056

1057

1058

1059

1060

1061

1062

1063

1064

1065

1066

1067

1068

1. Vienna, Austria: R Foundation for Statistical Computing.

Terry, R. L. (1970). Primate grooming as a tension reduction mechanism. The Journal of psychology, 76, 129-136. doi: 10.1080/00223980.1970.9916830

Theuerkauf, J., Rouys, S., Mériot, J. M., Gula, R., \& Kuehn, R. (2009). Cooperative breeding, mate guarding, and nest sharing in two parrot species of New Caledonia. Journal of Ornithology, 150, 791-797.

Tokuyama, N., \& Furuichi, T. (2016). Do friends help each other? Patterns of female coalition formation in wild bonobos at Wamba. Animal Behaviour, 119, 27-35. Doi:

10.1016/j.anbehav.2016.06.021

Tomaszycki, M. L., \& Zatirka, B. P. (2014). Same-sex partner preference in zebra finches: pairing flexibility and choice. Archives of Sexual Behavior, 43, 1469-1475.

Troisi, A., Schino, G., \& Aureli, F. (1989). Allogrooming and interindividual proximity in two species of macaques (Macaca fascicularis and M. nemestrina). Behaviour, 196-207.:

Val-Laillet, D., Guesdon, V., Von Keyserlingk, M. A., De Passillé, A. M., \& Rushen, J. (2009). Allogrooming in cattle: relationships between social preferences, feeding displacements and social dominance. Applied Animal Behaviour Science, 116, 141-149. doi: 10.1016/j.applanim.2008.08.005

Ventura, R., Majolo, B., Koyama, N. F., Hardie, S., \& Schino, G. (2006). Reciprocation and interchange in wild Japanese macaques: grooming, cofeeding, and agonistic support. American Journal of Primatology: Official Journal of the American Society of Primatologists, 68, 1138-1149. doi:10.1002/ajp.20314 
Vincze, O., Vágási, C. I., Kovács, I., Galván, I., \& Pap, P. L. (2013). Sources of variation in uropygial gland size in European birds. Biological Journal of the \# Linnean Society, 110, 543-563. doi: 10.1111/bij.12139

von Bayern, A. M., de Kort, S. R., Clayton, N. S., \& Emery, N. J. (2007). The role of food-and object-sharing in the development of social bonds in juvenile jackdaws (Corvus monedula). Behaviour, 711-733.

Watts, D. P. (2000). Grooming between male chimpanzees at Ngogo, Kibale National Park. I. Partner number and diversity and grooming reciprocity. International Journal of Primatology, 21, 189-210.

Wechsler, B. (1989). Measuring pair relationships in jackdaws. Ethology, 80(1-4), 307-317.

Wilson, K. A., Field, R., \& Wilson, M. H. (1995). Successful nesting behavior of Puerto Rican parrots. The Wilson Bulletin, 518-529.

Wittig, R. M., Crockford, C., Lehmann, J., Whitten, P. L., Seyfarth, R. M., \& Cheney, D. L. (2008). Focused grooming networks and stress alleviation in wild female baboons. Hormones and Behavior, 54, 170-177. doi: 10.1016/j.yhbeh.2008.02.009

Wright, J. (1998). Helpers-at-the-nest have the same provisioning rule as parents: experimental evidence from play-backs of chick begging. Behavioral Ecology and Sociobiology, 42, 423-429.

Young, C., Majolo, B., Heistermann, M., Schülke, O., \& Ostner, J. (2014). Responses to social and environmental stress are attenuated by strong male bonds in wild macaques. Proceedings of the National Academy of Sciences, 111, 18195-18200. doi: 10.1073/pnas.1411450111

Zabel, C. J., Glickman, S. E., Frank, L. G., Woodmansee, K. B., \& Keppel, G. (1992). Coalition 

and other Animals, 113-135.

Table 1.

1096 Number of individuals, group composition, study duration (number of months data collection 1097 period consisted of), average observation time/bird (rounded to nearest hr), data collection 1098 methods for social behaviors and proximity, and distance criteria used to identify nearest neighbor 1099 during proximity scans for study groups (Parrots/corvids, $N=15$ species; Pan species, $N=2$ ).

1100

\begin{tabular}{|c|c|c|c|c|c|c|c|}
\hline Taxa & Species & $N$ & $\begin{array}{l}\text { Group } \\
\text { compo- } \\
\text { sition }\end{array}$ & $\begin{array}{l}\text { Study } \\
\text { duration } \\
\text { (mos) and } \\
\text { hrs of } \\
\text { observation } \\
\text { /individual }\end{array}$ & $\begin{array}{l}\text { Method for } \\
\text { social behavior }\end{array}$ & $\begin{array}{l}\text { Method } \\
\text { for } \\
\text { proximity }\end{array}$ & $\begin{array}{l}\text { Nearest neighbor } \\
\text { criteria }\end{array}$ \\
\hline \multirow{8}{*}{ Parrot } & $\begin{array}{l}\text { Black-headed } \\
\text { caique }\end{array}$ & 4 & $A, \mathbf{N B}$ & 2,3 & $\mathbf{F}$ & NA & NA \\
\hline & $\begin{array}{l}\text { Blue and gold } \\
\text { macaw }\end{array}$ & 12 & $\mathbf{A}, \mathbf{N B}$ & 4,4 & $\mathbf{F}$ & $\mathbf{F}$ & NR \\
\hline & $\begin{array}{l}\text { Blue-throated } \\
\text { macaw }\end{array}$ & & & & & & \\
\hline & Group 2 & 7 & $\mathrm{~A}, \mathrm{NB}$ & 8,4 & GS & $\mathrm{G}$ & $\begin{array}{l}\text { DR, physical } \\
\text { contact }\end{array}$ \\
\hline & $\begin{array}{l}\text { Great green } \\
\text { macaw }\end{array}$ & & & & & & \\
\hline & Group 1 & 3 & $\mathrm{~A}, \mathrm{NB}$ & 1,4 & GS & G & $\begin{array}{l}\text { DR, physical } \\
\text { contact }\end{array}$ \\
\hline & Group 2 & 6 & $\mathrm{~A}, \mathrm{NB}$ & 10,4 & GS & $\mathrm{G}$ & $\begin{array}{l}\text { DR, physical } \\
\text { contact }\end{array}$ \\
\hline & $\begin{array}{l}\text { Orange-winged } \\
\text { Amazon }\end{array}$ & 23 & $\mathrm{~A}, \mathrm{NB}$ & 5,4 & $\mathbf{F}$ & $\mathbf{F}$ & NR \\
\hline
\end{tabular}




$\begin{array}{lllllll}\text { Red shouldered } & 4 & \text { A, NB } & \mathbf{2 , 3} & \text { F } & \text { na } & \text { NA } \\ \text { macaw } & & & & \end{array}$

$\begin{array}{lcccccc}\begin{array}{l}\text { Azure-winged } \\ \text { magpie }\end{array} & & & & & \\ \text { Group } 1 & 6 & \text { A, BP } & 4,4 & \text { F } & \text { F } & \text { NR } \\ \text { Group 2 } & 6 & \text { A, NB } & 5,6 & \text { F } & \text { F } & \text { NR }\end{array}$

\section{Common raven}

\begin{tabular}{|c|c|c|c|c|c|c|c|}
\hline & Group 1 & 8 & $\mathrm{~A}, \mathrm{NB}$ & 7,5 & $\mathrm{~F}$ & $\mathrm{~F}$ & NR \\
\hline \multirow{12}{*}{ Corvid } & Group 2 & 8 & $\mathrm{~A}, \mathrm{NB}$ & 7,5 & $\mathrm{~F}$ & $\mathrm{~F}$ & NR \\
\hline & Group 3 & 10 & $\mathrm{~J}$ & 10,8 & $\mathrm{~F}$ & $\mathrm{~F}$ & $\mathrm{NU}$ \\
\hline & Eurasian jay & 14 & $\mathbf{J}$ & 6,15 & GA & $\mathbf{G}$ & $\mathbf{N U}$ \\
\hline & Jackdaw & & & & & & \\
\hline & Group 1 & 10 & $\mathrm{~A}, \mathrm{NB}$ & 18,64 & GA & G & $\begin{array}{l}\text { DR, within } 2 \\
\text { body lengths }\end{array}$ \\
\hline & Group 2 & 15 & $\mathrm{~J}$ & 12,22 & GA & G & NU \\
\hline & $\begin{array}{l}\text { New } \\
\text { Caledonian } \\
\text { crow }\end{array}$ & 3 & МА, BP & 1,2 & $\mathbf{F}$ & $\mathbf{F}$ & NR \\
\hline & Rook & & & & & & \\
\hline & Group 1 & 14 & $\mathrm{~A}, \mathrm{BP}$ & 21,24 & $\mathrm{~F}$ & $\mathrm{G}$ & $\mathrm{NU}$ \\
\hline & Group 2 & 9 & $\mathrm{~A}, \mathrm{NB}$ & 17,64 & GA & G & $\begin{array}{l}\text { DR, within } 2 \\
\text { body lengths }\end{array}$ \\
\hline & Group 3 & 12 & $\mathrm{~A}, \mathrm{NB}$ & 18,62 & GA & $\mathrm{G}$ & $\begin{array}{l}\text { DR, within } 2 \\
\text { body lengths }\end{array}$ \\
\hline & Group 4 & 13 & $\mathrm{~J}$ & 12,34 & GA & $\mathrm{G}$ & $\mathrm{NU}$ \\
\hline
\end{tabular}

Bonobos

$\begin{array}{cccccc} & \text { Group 1 } & 11 & \text { MA } & 2,15 & \text { F } \\ \text { Apes } & \text { Group 2 } & 13 & \text { A } & 2,49 & \text { GS } \\ & \text { Group 3 } & 6 & \text { A } & 2,40 & \text { GS } \\ & \text { Group 4 } & 8 & \text { A } & 3,32 & \text { GS }\end{array}$

\section{Chimpanzees}

$\begin{array}{lllll}\text { Group 1 } & 8 & \text { MA } & 1,10 & \text { F } \\ \text { Group 2 } & 7 & \text { A } & 2,51 & \text { GS } \\ \text { Group 3 } & 17 & \text { A } & 3,36 & \text { GS }\end{array}$




$\begin{array}{lllll}\text { Group } 4 & 6 & \text { A } & 3,25 & \text { GS } \\ \text { Group 5 } & 18 & \text { A } & 12,51 & \text { GS \& GA }\end{array}$

Note. Groups were either composed of adult only (A), mixed-age (MA), or juvenile only (J). For birds, groups had either no breeding pairs (NB) or having one or more breeding pairs (BP). Data collection methods for social behaviors (allopreening/grooming, agonistic, active feed) consisted of individual focal (F), group all-occurrence (GA), or group scan (GS) sampling; for one ape group, group all-occurrence data and scan sampling data were available. For birds, data collection methods for proximity (nearest neighbor) consisted of individual focal (F) or group (G) scans; criteria used for identifying nearest neighbors consisted of distance requirements (DR), where individuals would have to be within a certain distance of one another in order to be considered nearest neighbors, or no distance requirement (NR), where an individual that was closest in physical proximity to a subject was considered the subject's nearest neighbor; minimum distance criteria is indicated for groups where a distance requirement was used. NA indicates that proximity data were not available, while NU indicates that proximity data were available but not used in GLMMs because study groups did not have data on the other factors included in the models or because they were juvenile groups and were thus not included in GLMMs. The mean number of observation hours/individual is used for groups where observation time varied between individuals.

\section{Table 2.}

Results of Models $1 a, 1 b$, and $1 c$ which examined whether taxon could explain variation in time dedicated to social grooming as measured by proportion of time spent social grooming (1a), proportion of scans spent social grooming (1b) and rate of social grooming initiations (1c). Models 1a-c varied in the number of groups of birds and Pan species they included: Model 1a had 11 bird groups and three Pan groups; Model $1 \mathrm{~b}$ had four bird groups and seven Pan groups; Model 1c had 16 bird groups and two Pan groups. The table shows estimates (est.), together with odds ratios (OR), standard errors (SE), confidence limits (CI), significance tests as well as minimum and maximum of model estimates obtained when dropping levels of random effects one at a time).

\begin{tabular}{|c|c|c|c|c|c|c|c|c|c|c|c|}
\hline Model & Term & est. & OR & $\mathrm{SE}$ & lower $\mathrm{Cl}$ & upper $\mathrm{Cl}$ & $\chi^{2}$ & $\mathrm{df}$ & $\mathrm{P}$ & $\min$ & Max \\
\hline $1 \mathrm{a}$ & Intercept & -2.111 & 0.121 & 0.464 & -3.084 & -1.077 & & & (1) & -2.381 & -0.970 \\
\hline $1 \mathrm{a}$ & $\operatorname{taxon}^{(2)}$ & -1.634 & 0.195 & 0.378 & -2.423 & -0.814 & 7.813 & 1 & 0.005 & -2.059 & -1.350 \\
\hline $1 \mathrm{a}$ & gr. Size & 0.009 & 1.009 & 0.030 & -0.056 & 0.071 & 0.050 & 1 & 0.822 & -0.090 & 0.029 \\
\hline $1 b$ & Intercept & -2.027 & 0.132 & 0.146 & -2.353 & -1.726 & & & (1) & -2.171 & -1.892 \\
\hline $1 b$ & $\operatorname{taxon}^{(2)}$ & -0.722 & 0.486 & 0.337 & -1.418 & -0.044 & 3.655 & 1 & 0.056 & -1.001 & -0.452 \\
\hline $1 b$ & z.gr. size ${ }^{(3)}$ & 0.063 & 1.066 & 0.152 & -0.280 & 0.420 & & & & -0.222 & 0.144 \\
\hline
\end{tabular}


1c $\operatorname{taxon}^{(2)}$

$\begin{array}{llll}-0.423 & 0.655 & 0.552 & -1.532\end{array}$

0.724

0.576

0.448

$-0.612$

$-0.318$

1c gr. Size

$\begin{array}{llll}0.002 & 1.002 & 0.035 & -0.061\end{array}$

0.069

0.003

$\begin{array}{ll}0.954 & -0.043\end{array}$

(2) dummy coded with ape being the reference category

(3) $\mathrm{z}$-transformed to a mean of zero and a standard deviation of one; mean and sd of the original variable were 10.383 and 5.350; no test indicated as the model lacking group size did not converge

1134

1135

1136

1137

1138

1139

1140

1141

1142

\section{Table 3.}

Medians (Mdn) and interquartile ranges (IQR) of social grooming rate (Corvids/parrots $N=16$ groups from 12 species; Pan species $N=$ two groups from two species) and proportion of time (Corvids/parrots, $N=11$ groups from nine species; Pan species $N=$ three groups from two species) or scans (Corvids/parrots, $N=$ four groups from two species; Pan species $N=$ seven groups from two species) subjects spent socially grooming, for all individuals included in the GLMMs comparing birds and Pan species.

\begin{tabular}{llccccc} 
& \multicolumn{2}{c}{ Birds (Parrots \& Corvids) } & \multicolumn{3}{c}{ Apes (Pan species) } \\
\cline { 2 - 7 } & $N$ & $M d n$ & $I Q R$ & $N$ & $M d n$ & $I Q R$ \\
\hline Rate of grooming initiations & 156 & .02 & .07 & 19 & .06 & .04 \\
$\begin{array}{l}\text { Proportion of time spent } \\
\text { grooming (Duration) }\end{array}$ & 88 & .01 & .04 & 37 & .09 & .09 \\
$\begin{array}{l}\text { Proportion of time spent } \\
\text { grooming (Scans) }\end{array}$ & 19 & .03 & .05 & 75 & .12 & .12 \\
\end{tabular}

Table 4.

1146 Results of Models $2 a$ and $b$ which examined whether taxon could explain variation in the proportion of group members an individual engaged in grooming with. Model $2 b$ controlled for group size by including the number of potential partners (nr.partn.) as a fixed factor. Both models included data from 13 groups of nine bird species and nine groups of two Pan species. Table shows estimates (est.), together with odds ratios (OR), standard errors (SE), confidence 1151 limits, significance tests as well as minimum and maximum of model estimates obtained when 1152 dropping levels of random effects one at a time.

\begin{tabular}{llrrrrrrrrrrr}
\hline Model & term & est. & OR & & SE & lower Cl & upper Cl & $\chi^{2}$ & df & P & $\min$ & $\max$ \\
\hline a & Intercept & -0.984 & 0.374 & 0.333 & -1.592 & -0.369 & & & $(1)$ & -1.087 & -0.874 \\
2a & taxon $^{(2)}$ & -0.369 & 0.691 & 0.391 & -1.104 & 0.357 & 0.811 & 1 & 0.368 & -0.500 & -0.258
\end{tabular}


$1153 \quad{ }^{(1)}$ not shown because of having a very limited interpretation

\begin{tabular}{llrlllllllll} 
2b & Intercept & 0.245 & 1.277 & 0.192 & -0.105 & 0.566 & & & (1) & 0.085 & 0.459 \\
$\mathrm{2b}$ & taxon $^{(2)}$ & -0.320 & 0.726 & 0.137 & -0.605 & -0.062 & 3.151 & 1 & 0.076 & -0.389 & -0.237 \\
$\mathrm{2b}$ & nr. partn. & 0.050 & 1.051 & 0.012 & 0.029 & 0.073 & 16.323 & $1<0.001$ & 0.032 & 0.062 \\
\hline
\end{tabular}

$1154{ }^{(2)}$ dummy coded with ape being the reference category

1155

1156

1157

1158

1159

1160

1161

1162

\begin{tabular}{lllr}
\hline & Birds & Apes & 1163 \\
& $(N=95$ focal animals $)$ & $(N=85$ focal anima1s $) 64$ \\
\hline Mean $(S D)$ & $1.78(1.94)$ & $2.73(1.69)$ & 1165 \\
Median $(I Q R)$ & $2(1)$ & $2(1)$ & 1166 \\
Range & $4(1$ to 5$)$ & $8(1$ to 9$)$ & 1167 \\
\hline
\end{tabular}

Table 5.

Descriptive statistics for number of different grooming partners birds (parrots and corvids: $N=$ 13 groups from nine species) and apes ( $N=$ nine groups from two Pan species) had in 240minute sample of observation time. $S D$ - standard deviation, IQR - inter quartile range 
Table 6.

1171 Descriptive statistics for species (birds (parrots/corvids), $N=15$; apes (Pan), $N=2$ ) and study

1172 group allopreening/grooming rate, percentage of time or scans spent allopreening/grooming,

1173 number of unique allopreening/grooming partners, and number of potential partners within the

1174 captive group.

1175

\begin{tabular}{|c|c|c|c|c|c|c|c|c|c|c|}
\hline \multirow[t]{2}{*}{$\begin{array}{l}\text { Family and age } \\
\text { groups }\end{array}$} & \multirow[t]{2}{*}{ Species } & \multicolumn{2}{|c|}{$\begin{array}{l}\text { Allopreen/groo } \\
\mathrm{m} \\
\text { rate } \\
\text { (bouts/min) }\end{array}$} & \multicolumn{2}{|c|}{$\begin{array}{l}\text { \% Time spent } \\
\text { Allopreening/ } \\
\text { Grooming }\end{array}$} & \multicolumn{2}{|c|}{$\begin{array}{l}\text { \% Scans } \\
\text { Allopreening/ } \\
\text { Grooming }\end{array}$} & \multicolumn{2}{|c|}{$\begin{array}{l}\text { No. of unique } \\
\text { partners in } \\
\text { first } 240 \text { min } \\
\text { observation }\end{array}$} & \multirow[t]{2}{*}{$\begin{array}{l}\text { No. of } \\
\text { potential } \\
\text { partners }\end{array}$} \\
\hline & & $M$ & $S D$ & $M$ & $S D$ & $M$ & $S D$ & $M$ & $S D$ & \\
\hline \multirow{16}{*}{$\begin{array}{l}\text { Parrot adult and } \\
\text { mixed age } \\
\text { groups }\end{array}$} & $\begin{array}{l}\text { Black-headed } \\
\text { caique }\end{array}$ & .02 & .01 & 0.35 & 0.45 & na & na & na & na & 3 \\
\hline & $\begin{array}{l}\text { Blue and gold } \\
\text { macaw }\end{array}$ & .21 & .21 & 6.11 & 5.43 & na & na & 1.36 & .67 & 11 \\
\hline & $\begin{array}{l}\text { Blue-throated } \\
\text { macaw }\end{array}$ & na & na & na & na & 4.00 & 4.61 & 1.88 & .83 & 4 \\
\hline & Group 1 & na & na & na & $\mathrm{Na}$ & 9.44 & 5.09 & 1.33 & .58 & 2 \\
\hline & Group 2 & na & na & na & $\mathrm{Na}$ & 1.67 & 1.44 & 2.20 & .84 & 6 \\
\hline & $\begin{array}{l}\text { Great green } \\
\text { macaw }\end{array}$ & na & na & na & na & 3.89 & 3.89 & 1.67 & .87 & 3.50 \\
\hline & Group 1 & na & na & na & $\mathrm{Na}$ & 8.33 & 3.63 & 1.33 & .58 & 2 \\
\hline & Group 2 & na & na & na & $\mathrm{Na}$ & 1.67 & 1.05 & 1.83 & .98 & 5 \\
\hline & Greater vasa & .03 & .03 & 0.11 & 0.05 & na & na & 1.88 & 1.46 & 9 \\
\hline & $\begin{array}{l}\text { Goffin's } \\
\text { cockatoo }\end{array}$ & .03 & .03 & na & na & na & na & 1.55 & .93 & 13 \\
\hline & Kea & .01 & .01 & na & na & na & na & na & na & 19.43 \\
\hline & $\begin{array}{l}\text { Orange- } \\
\text { winged } \\
\text { Amazon }\end{array}$ & .12 & .08 & 2.96 & 2.05 & na & na & 2.40 & .91 & 22 \\
\hline & $\begin{array}{l}\text { Red } \\
\text { shouldered } \\
\text { macaw }\end{array}$ & .23 & .07 & 8.73 & 3.68 & na & na & na & na & 3 \\
\hline & $\begin{array}{l}\text { Azure-winged } \\
\text { magpie }\end{array}$ & .03 & .04 & 0.26 & 0.48 & na & na & 1.43 & .53 & 4.90 \\
\hline & Group 1 & .03 & .05 & 0.29 & 0.68 & na & na & 1.50 & .71 & 4.80 \\
\hline & Group 2 & .03 & .03 & 0.18 & 0.17 & na & na & 1.40 & .55 & 5 \\
\hline
\end{tabular}




\begin{tabular}{|c|c|c|c|c|c|c|c|c|c|c|}
\hline \multirow{9}{*}{$\begin{array}{l}\text { Corvid adult and } \\
\text { mixed age } \\
\text { groups }\end{array}$} & $\begin{array}{l}\text { Common } \\
\text { raven }\end{array}$ & .07 & .05 & 0.66 & 0.00 & na & na & 1.87 & .92 & 7 \\
\hline & Group 1 & .06 & .04 & 0.48 & 0.00 & na & na & 2.13 & 1.13 & 7 \\
\hline & Group 2 & .08 & .06 & 0.87 & 0.47 & na & na & 1.86 & 1.07 & 7 \\
\hline & Jackdaw & .00 & .00 & na & na & na & na & na & na & 9 \\
\hline & $\begin{array}{l}\text { New } \\
\text { Caledonian } \\
\text { crow }\end{array}$ & .07 & .05 & 1.15 & 1.18 & na & na & na & na & 2 \\
\hline & Rook & .02 & .03 & & & na & na & & & 10.23 \\
\hline & Group 1 & .04 & .04 & 3.18 & 2.33 & na & na & 1.36 & .51 & 11.70 \\
\hline & Group 2 & .00 & .00 & na & $\mathrm{Na}$ & na & na & na & na & 8 \\
\hline & Group 3 & .01 & .01 & na & $\mathrm{Na}$ & na & na & na & na & 11 \\
\hline \multirow{4}{*}{$\begin{array}{l}\text { Juvenile corvid } \\
\text { groups }\end{array}$} & Eurasian jay & .00 & .00 & na & na & na & na & na & na & 13 \\
\hline & $\begin{array}{l}\text { Common } \\
\text { raven }\end{array}$ & .05 & .04 & 1.01 & .95 & na & na & & & 9 \\
\hline & Jackdaw & .03 & .01 & na & na & na & na & na & na & 14 \\
\hline & Rooks & .06 & .04 & na & na & na & na & na & na & 12 \\
\hline \multirow{11}{*}{ Apes } & Bonobos & & & & & & & & & \\
\hline & Group 1 & .06 & .03 & 13.79 & 5.19 & na & na & 2.36 & 1.57 & 10 \\
\hline & Group 2 & na & na & na & na & 12.77 & 7.11 & 2.00 & .82 & 12 \\
\hline & Group 3 & na & na & na & na & 6.69 & 4.56 & 1.60 & .89 & 5 \\
\hline & Group 4 & na & na & na & na & 14.02 & 5.90 & 2.86 & 1.22 & 7 \\
\hline & Chimpanzees & & & & & & & & & \\
\hline & Group 1 & .07 & .03 & 17.05 & 7.89 & na & na & 2.50 & 1.20 & 7 \\
\hline & Group 2 & na & na & na & na & 3.93 & 2.26 & 2.20 & .45 & 6 \\
\hline & Group 3 & na & na & na & na & 17.10 & 10.67 & 4.24 & 2.44 & 16 \\
\hline & Group 4 & na & na & na & na & 15.58 & 7.39 & 1.60 & .55 & 5 \\
\hline & Group 5 & na & na & 6.83 & 0.04 & 10.12 & 5.61 & 2.76 & 1.35 & 17 \\
\hline
\end{tabular}

1176 Note. Number of potential partners refers to the number of individuals who co-occurred with 1177 focal animals in observations of that specific group. The mean number of potential allopreening 1178 partners (calculated across observations) is used for groups where the group size varied due to 1179 changes in group composition. 
Table 7

1182 Results of Models $3 a$ and $b$ which examined if variation in whether or not a dyad engaged in allopreening could be explained by other dyadic social behaviours. Model 3 a included as fixed factors the proportion of time spent in close proximity, the occurrence of active feeding, and the occurrence of agonistic interactions. Model $3 b$ only included proximity and active feeding as fixed effects. Models $3 a$ and $3 b$ included seven and 11 bird groups, respectively. The table shows estimates (est.), together with odds ratios (OR), standard errors (SE), confidence limits, significance tests as well as minimum and maximum of model estimates obtained when dropping levels of random effects one at a time.

\begin{tabular}{|c|c|c|c|c|c|c|c|c|c|c|c|}
\hline Model & term & est. & OR & SE & lower $\mathrm{Cl}$ & upper $\mathrm{Cl}$ & $\chi^{2}$ & df & $\mathrm{P}$ & $\min$ & $\max$ \\
\hline $3 a$ & Intercept & -4.966 & 0.007 & 0.539 & -21.359 & -4.435 & & & (1) - & -17.679 & -4.484 \\
\hline $3 a$ & feeding $^{(2)}$ & -1.424 & 0.241 & 1.321 & -14.368 & 1.295 & 1.397 & 1 & 0.237 & -9.630 & 0.229 \\
\hline $3 a$ & $\operatorname{agon}^{(3)}$ & -0.400 & 0.670 & 0.696 & -6.751 & 0.625 & 0.384 & 1 & 0.535 & -5.283 & 0.021 \\
\hline $3 a$ & proximity $^{(4)}$ & 3.825 & 45.854 & 1.287 & 1.682 & 24.860 & 6.439 & 1 & 0.011 & 2.319 & 23.457 \\
\hline $3 b$ & Intercept & -6.174 & 0.002 & 0.678 & -9.830 & -5.114 & & & (1) & -6.877 & -5.538 \\
\hline $3 b$ & feeding $^{(2)}$ & 0.598 & 1.818 & 1.457 & -3.325 & 4.047 & 0.159 & 1 & 0.690 & -1.074 & 1.031 \\
\hline $3 b$ & proximity $^{(4)}$ & 4.000 & 54.624 & 0.781 & 2.629 & 7.831 & 13.801 & 1 & 0.000 & 3.024 & 4.774 \\
\hline
\end{tabular}

${ }^{(1)}$ not shown because of having a very limited interpretation

(2) dummy coded with no feeding observed being the reference category

$1191{ }^{(3)}$ dummy coded with no agonistic behaviors observed being the reference category

$1192{ }^{(4)}$ z-transformed to a mean of zero and a standard deviation of one; mean and sd of the original variable 1193 were 0.044 and 0.115 (Model 3a) and 0.046 and 0.113 (Model 3b), respectively

Table 8.

1196 Percentage of preening behaviors subjects $(N=7$ species) directed to partners that focused on 1197 preening the head/neck area) and anatomical preening mechanism ( $G=$ urypoigal gland, $P=$ 1198 powder down) per species.

$$
\% \text { head Mechanism }
$$

\begin{tabular}{lcl}
\hline Blue and gold macaw & 55.72 & G (Vincze et al., 2013) \\
Blue-throated macaw & 72.50 & G (Abramson et al., 1995) \\
Great-green macaw & 50.00 & G (Lambert, personal communication) \\
Greater vasa & 50.00 & G (Christian, 2000)
\end{tabular}



Common raven
50.65
G (Montalti \& Salibián, 2000)
New Caledonian crow
65.00
G (Montalti \& Salibián, 2000) ${ }^{\dagger}$
Orange-winged
76.14
P (Vincze et al., 2013)
amazon

Note. Percentages for blue-throated and great-green macaws were calculated using scan frequency data (number of scans in which A preened B's head divided by total number of scans during which A preened B, regardless of region); for all other species, percentages were calculated using frequency data obtained via all-occurrence sampling (total frequency of head preening given by A to B divided by total frequency of preening given by A to B, regardless of region). ${ }^{\dagger}$ Montalti and Salibián, (2000) report presence of uropygial glands in species closely related to New Caledonian crows (e.g., Carrion crows, Corvus corone); a source could not be found that reports presence or absence of uropygial glands specifically in New Caledonian crows.

\section{Table 9.}

Results of Models $4 a$ and $b$ which examined whether variation in the occurrence of head (4a) or body (4b) preening within a dyad could be explained by the occurrence of active feeding and the proportion of time in close proximity. Table shows estimates (est.), together with odds ratios $(O R)$, standard errors (SE), confidence limits, significance tests as well as minimum and maximum of model estimates obtained when dropping levels of random effects one at a time.

\begin{tabular}{|c|c|c|c|c|c|c|c|c|c|c|c|}
\hline Model & $\mathrm{rm}$ & est. & $\mathrm{SE}$ & OR & $C 1$ & & $\chi^{2}$ & c & $\mathrm{P}$ & $\min$ & $\max$ \\
\hline$(\mathrm{H})$ & Intercept & .257 & 978 & .005 & 32 & -4.277 & & & (1) & -24 & 1807 \\
\hline & & 443 & 1.622 & 176 & 2.947 & .825 & 14.769 & & .001 & & 20.312 \\
\hline (H) & 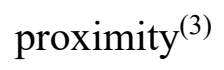 & 8 & 1.7924 & 4.134 & 7 & .626 & .580 & & .001 & & .705 \\
\hline H) & spec & 0 & 1.003 & 586 & & 12.425 & 08 & & 001 & 75 & 7.032 \\
\hline (H) & m & 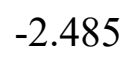 & 2 & 083 & 21150 & 126 & & & & 03 & -0.746 \\
\hline a (B) & Inte & & 0.496 & 15 & & & & & (1) & & -3.959 \\
\hline (B) & feedi & 1 & 32 & 667 & & & 30 & 1 & 0.501 & & 2.403 \\
\hline (B) & proxin & & & 8.011 & & & 3 & & $<0.001$ & & 15 \\
\hline a (B) & 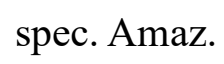 & 108 & 0.776 & 0.302 & -12.124 & 8 & 2.789 & 2 & 0.248 & 07 & -0.934 \\
\hline a (B) & Spec. Vasa & -0.978 & 0.701 & 0.376 & -19.852 & 0.699 & & & & -1.563 & -0.774 \\
\hline
\end{tabular}

${ }^{(1)}$ not shown because of having a very limited interpretation

(2) dummy coded with no feeding observed being the reference category; the large odds ratio arises from effects being fairly extreme (see Fig. 4)

(3) $\mathrm{z}$-transformed to a mean of zero and a standard deviation of one; mean and sd of the original variable were 0.093 and 0.152 , respectively; the large odds ratio arises from effects being fairly extreme (see Fig. 4) 
$1221{ }^{(4)}$ dummy coded with Blue and gold macaw being the reference category; the indicated test refers to the 1222 overall effect of species

1223

1224

1225

1226 
Figure legends
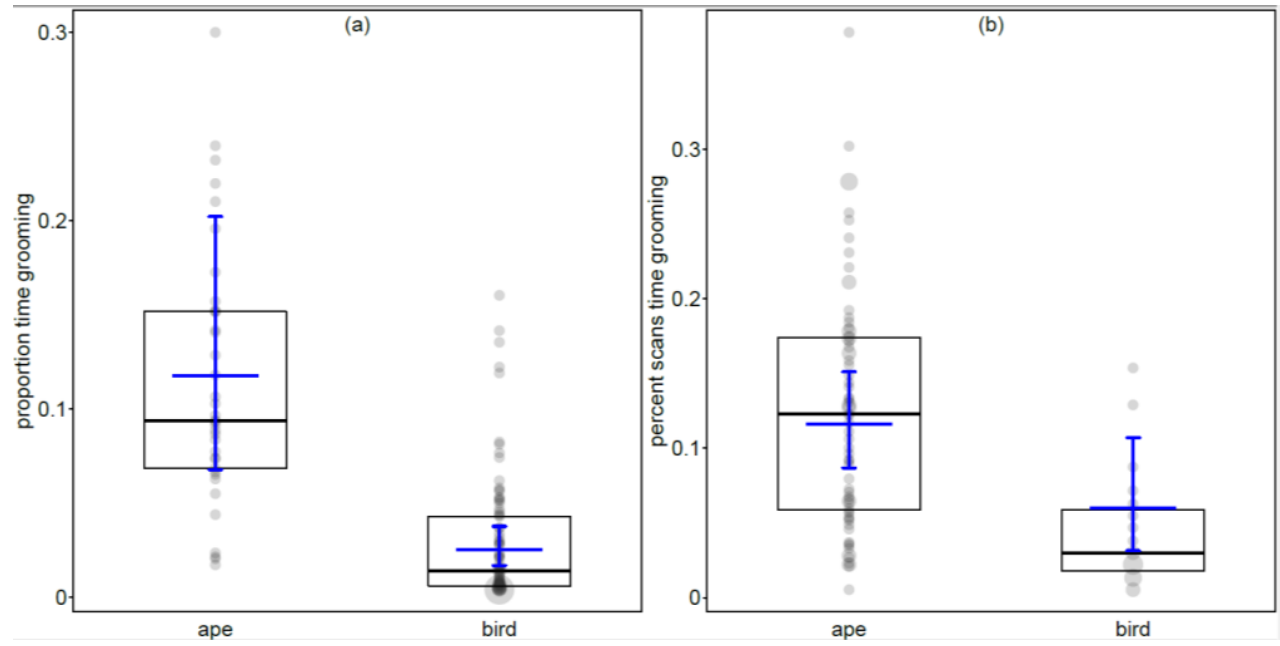

Figure 1. Proportion time (a) and percent scans (b) spent grooming, separately for apes (chimpanzees/bonobos) and birds (corvids/parrots). Depicted are the raw data (grey dots), whereby the area of the dots is proportionate to the number of observations per value of the response $(N=1$ to 9). Thick black horizontal lines and boxes depict medians and quartiles, and the blue vertical line with error bars depicts the fitted model and its confidence intervals. Corvids and parrots spent a significantly smaller proportion of their time grooming than Pan species (a) and also tended to spend fewer scans grooming than Pan species (b).

1236

1237 


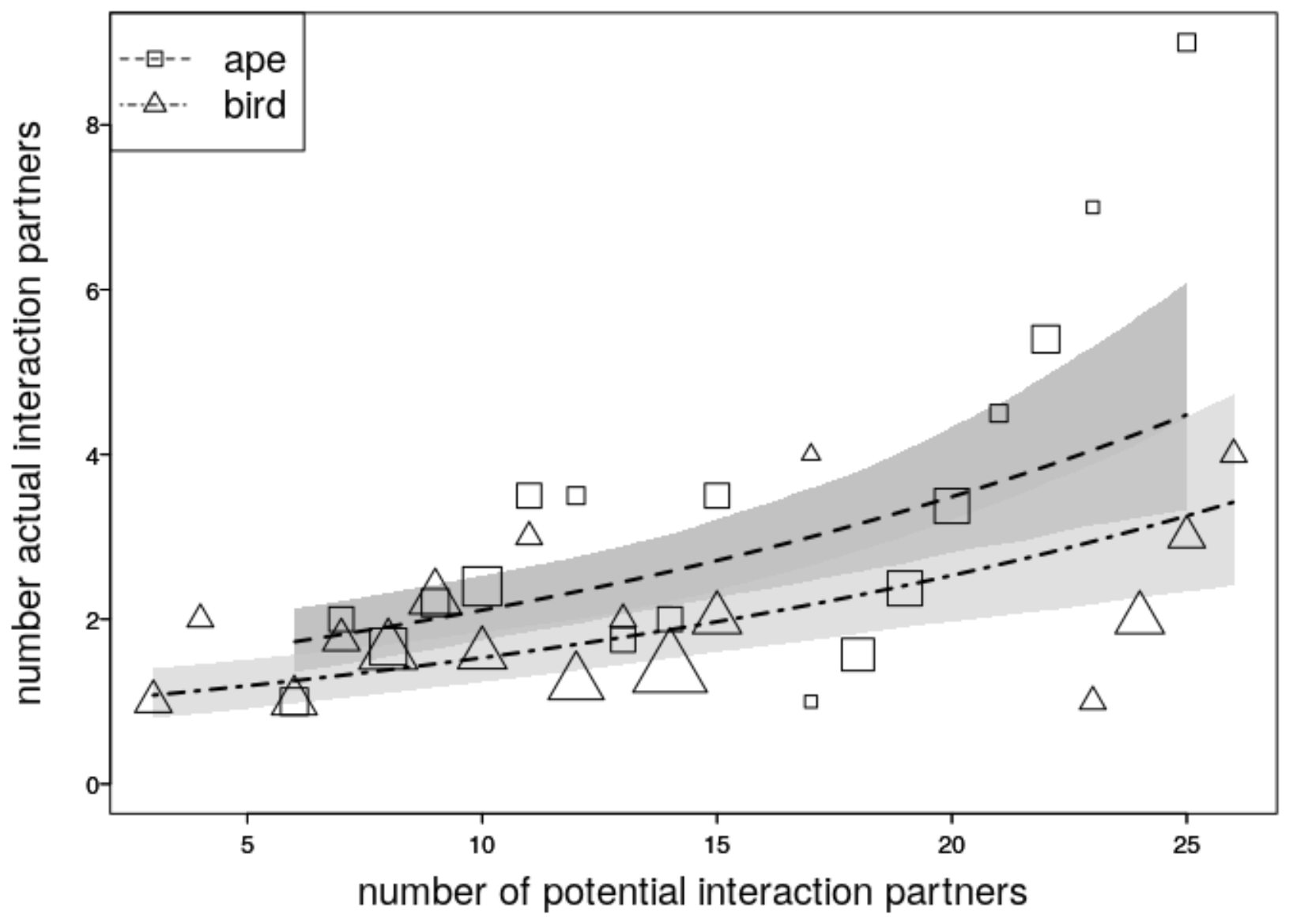

1239 Figure 2. Number of grooming interaction partners as a function of the number of potential 1240 interaction partners, and separately for birds (corvids/parrots) and apes (chimpanzees/bonobos).

1241 Indicated are average numbers of interaction partners per number of potential interaction 1242 partners, whereby the area of the dots corresponds to the number of observations per taxon and 1243 number of potential interaction partners $(N=1$ to 16$)$. The dotted lines depict the fitted model 1244 and the shaded areas its confidence interval. As group size increased the number of grooming 1245 partners increased and when controlling for group size parrots and corvids tended to have fewer 1246 grooming interaction partners than Pan species. 

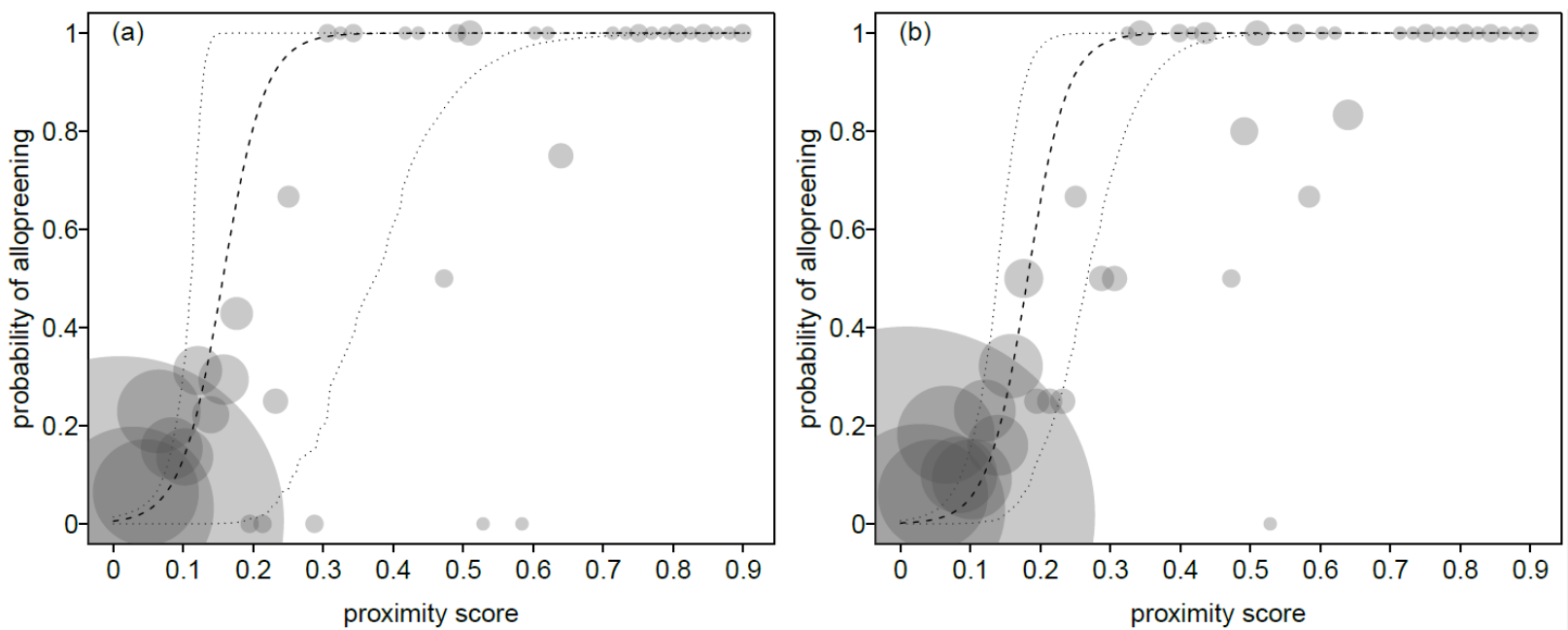

1249

1250

1251

1252

1253

1254

1255

1256

1257

1258

1259

1260

1261

1262

1263

1264

1265

1266

1267

1268

1269

1270

Figure 3. Probability of dyadic allopreening to be observed within a given dyad, as a function of their proximity score. (a) illustrates the relationship from Model 3a where proximity, active feeding and agonistic interactions were included as fixed factors $(N=77$ individuals from six species) and (b) illustrates the relationship from Model $3 \mathrm{~b}$ where just proximity and active feeding were included as fixed factors ( $N=118$ individuals from nine species). Each dot shows the average probability per bin of the proximity score, whereby the area of the dots depicts the number of dyads per $\operatorname{dot}(N=1$ to 1005$)$. The dashed and dotted lines depict the fitted model and its confidence interval (with all other predictors in the model being at their average and assuming an observation effort of $4 \mathrm{hrs}$, which roughly equals the average observation effort). The two plots differ in the amount of data used and the additional predictors being present in the model. In both models, allopreening was more likely to occur in dyads that spent a higher proportion of their time in close physical proximity.
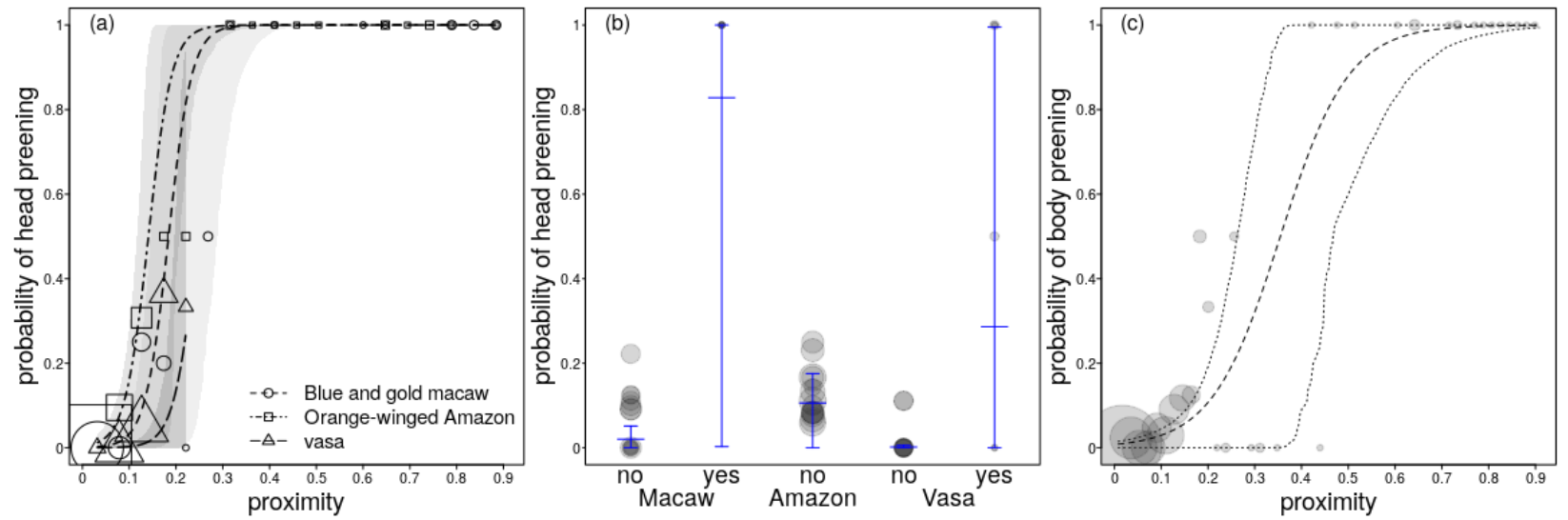

Figure 4. Probability of head preening (a, b) and body preening (c) as a function of dyadic proximity $(\mathrm{a}, \mathrm{c})$ or separately for three species and dyads that exhibited or did not exhibit active feeding (b). Dots in (a) and (c) show the average probability per bin of the dyadic proximity, and dots in (b) depict average probability per individual. The area of the dots is proportionate to the number of dyads per dot (range, a: 1 to 147 ; b: 1 to 18 ; c: 1 to 154 ). The fitted model and its 
1271 confidence intervals are depicted by dashed lines and shaded areas (a), vertical blue lines with 1272 error bars (b), or the dashed and dotted line (c). Head preening (a) and body preening (c) was more 1273 likely to occur in dyads that spent a high proportion of their time in close proximity and in macaws 1274 and vasas who exhibited active feeding, head preening was more likely in dyads who also engaged 1275 in active feeding (b).

1276

1277

1278

1279 